University of South Florida

DIGITAL COMMONS

Digital Commons @ University of

@ UNIVERSITY OF SOUTH FLORIDA

South Florida

School of Geosciences Faculty and Staff

Publications

School of Geosciences

$5-2020$

\title{
Surface Deformation and Induced Seismicity Due to Fluid Injection and Oil and Gas Extraction in Western Texas
}

\author{
Fanghui Deng \\ University of South Florida, fanghuideng@mail.usf.edu \\ Timothy H. Dixon \\ University of South Florida, thd@usf.edu \\ Surui Xie \\ University of South Florida, suruixie@mail.usf.edu
}

Follow this and additional works at: https://digitalcommons.usf.edu/geo_facpub

Part of the Earth Sciences Commons

\section{Scholar Commons Citation}

Deng, Fanghui; Dixon, Timothy H.; and Xie, Surui, "Surface Deformation and Induced Seismicity Due to Fluid Injection and Oil and Gas Extraction in Western Texas" (2020). School of Geosciences Faculty and Staff Publications. 2266.

https://digitalcommons.usf.edu/geo_facpub/2266

This Article is brought to you for free and open access by the School of Geosciences at Digital Commons @ University of South Florida. It has been accepted for inclusion in School of Geosciences Faculty and Staff Publications by an authorized administrator of Digital Commons @ University of South Florida. For more information, please contact digitalcommons@usf.edu. 


\section{JGR Solid Earth}

\section{RESEARCH ARTICLE 10.1029/2019JB018962 \\ Key Points: \\ - Increasing numbers of earthquakes in recent years south and southeast of Pecos city, Texas, are likely related to oil and gas production \\ - InSAR time series deformation was used to distinguish the causes of deformation and to estimate media properties and reservoir dynamics \\ - Numerical modeling suggests that pore pressure change due to fluid injection is likely the main contributor to the abnormal earthquakes}

Supporting Information:

- Supporting Information S1

Correspondence to:

F. Deng,

fanghuideng@mail.usf.edu

Citation:

Deng, F., Dixon, T. H., \& Xie, S. (2020) Surface deformation and induced seismicity due to fluid injection and oil and gas extraction in western Texas. Journal of Geophysical Research: Solid Earth, 125, e2019JB018962. https://doi org/10.1029/2019JB018962

Received 27 OCT 2019 Accepted 13 APR 2020 Accepted article online 21 APR 2020

(C)2020. American Geophysical Union. All Rights Reserved.
Surface Deformation and Induced Seismicity Due to Fluid Injection and Oil and Gas Extraction in Western Texas

\author{
Fanghui Deng ${ }^{1}$ D, Timothy H. Dixon ${ }^{1}$ (D), and Surui Xie ${ }^{1}$ (D) \\ ${ }^{1}$ School of Geosciences, University of South Florida, Tampa, FL, USA
}

\begin{abstract}
Texas is experiencing increasing seismicity, likely related to the oil and gas production process. We used satellite InSAR (Interferometric Synthetic Aperture Radar) to monitor surface deformation at three study sites in western Texas with similar geologic characteristics. The deformation data were compared to earthquake distribution, groundwater changes, volumes of produced and injected fluid, and calculated pore pressure change and Coulomb failure stress change to assess causes of deformation and seismicity. Site 1 experienced surface uplift due to fluid injection but no increase in seismicity. The average media properties were estimated based on the deformation using a poroelastic model. Site 2 experienced subtle surface subsidence and elevated seismicity. Subsidence here might reflect groundwater withdrawal. Simulated pore pressure changes using MODFLOW suggest the earthquakes are likely induced by fluid injection. Site 3 experienced significant surface subsidence and seismicity. InSAR time series, water level data, and oil/gas extraction history suggest that subsidence in the northern part of this site reflects oil/gas extraction, while subsidence in the southern part is mainly due to groundwater withdrawal. An Okada tensile model was used to derive the equivalent source strength causing the subsidence, then Coulomb failure stress changes associated with this source were calculated. We found that pore pressure change (simulated using MODFLOW) due to fluid injection is likely the main contributor to elevated seismicity at this site. Variations in oil/gas production activity, seismicity, and surface deformation between our three sites suggest the importance of local rock structure and media properties in determining susceptibility to induced seismicity.
\end{abstract}

Plain Language Summary In recent years, both oil/gas production and earthquake number have increased in western Texas. This coincidence suggests at least some of the earthquakes are likely related to the oil/gas production process. We used sequential satellite images to measure surface deformation at three study sites in the Delaware Basin, western Texas. These three sites show different patterns of surface deformation and earthquake occurrence: (1) Site 1 has obvious uplift but no earthquakes; (2) Site 2 has little subsidence but many earthquakes; (3) Site 3 has significant subsidence and earthquakes. By analyzing temporal and spatial correlations between multiple independent data sets and the results of numerical models, we found the likely causes of the deformation and elevated earthquakes: (1) Surface uplift at Site 1 is due to fluid injection; (2) surface subsidence and earthquakes at Site 2 are probably related to groundwater withdrawal and fluid injection, respectively; and (3) the obvious surface subsidence at Site 3 reflects groundwater withdrawal in the south and oil/gas extraction in the north, while earthquakes are likely related to fluid injection. Since our model results rely on subsurface media properties, better assessment of whether an earthquake was or was not induced will require better knowledge of local rock properties.

\section{Introduction}

The central and eastern United States, an unusual location for earthquakes, have undergone a dramatic increase in seismicity over the past one to two decades (Ellsworth, 2013; Keranen et al., 2014; Rubinstein \& Mahani, 2015; Weingarten et al., 2015). Many of these recent earthquakes were likely induced by human activity, such as impoundment of reservoirs (e.g., Johann et al., 2018; Peinke et al., 2006), mining (e.g., Boltz et al., 2014), fluid injection (e.g., Hincks et al., 2018; Shirzaei et al., 2016; Yeck et al., 2016), and oil and gas extraction (e.g., Frohlich \& Brunt, 2013).

Oil/gas extraction and fluid injection are the two main forms of mass transport in oil and gas fields. It has long been understood that earthquakes can be induced by underground fluid injection, which increases pore pressure, and can reduce effective normal stress on suitably oriented faults, allowing them to slide under 
preexisting shear stress (Raleigh et al., 1976). Oil and gas extraction can also induce earthquakes by contracting the reservoir rocks, deforming the surrounding rocks, changing local mass distribution, or otherwise changing the local stress field (Hough et al., 2017; Segall, 1989; Yerkes \& Castle, 1976). Among published research papers for earthquakes occurring in and around oil and gas fields, many more were interpreted to be related with fluid injection compared to oil and gas extraction.

In addition to seismicity, oil/gas extraction and fluid injection have been reported to cause surface deformation in some fields. However, surface deformation (unrelated to earthquake offset) and seismicity do not always co-occur. Surface deformation and seismicity have been observed together (e.g., Barnhart et al., 2014; Kim \& Lu, 2018; Segall, 1989, 1992; Yerkes \& Castle, 1976), but sometimes just one occurs (e.g., Karegar et al., 2015; Shirzaei et al., 2016; Yang et al., 2015). In some cases, neither surface deformation nor seismicity are observed despite significant oil/gas extraction or fluid injection.

The reasons for this wide range of behaviors are not well understood. Rates of injection or extraction, their durations and depths, subsurface media properties, and the presence or absence of preexisting weaknesses are all likely important factors. For example, if injection rate or duration of injection exceeds some threshold, earthquakes may be induced because the elevated stress is not able to diffuse away quickly enough via aseismic stress release processes (aseismic deformation or pore fluid diffusion). Seismic rate can be 0 or very low at the beginning of the injection but increase dramatically after several years of fluid injection (e.g., Goebel et al., 2017; Shirzaei et al., 2016; Walsh \& Zoback, 2015). Faults can act as preexisting weaknesses that focus seismicity (e.g., Yeck et al., 2017; Zhang et al., 2013). Stratigraphic boundaries with large permeability contrast, such as the contact between sedimentary overburden and crystalline basement, can suppress the spread of induced seismicity into the tighter confining formations by preventing pore pressure propagation (e.g., Barnhart et al., 2018; Shirzaei et al., 2016; Zhang et al., 2013).

Many studies use only the temporal and spatial correlations between injection/extraction activity and earthquake occurrence to infer whether the former is the cause of the latter. Here we use numerical models of the physical process to quantitatively assess the relation between induced seismicity and fluid injection/extraction. We investigated three sites in western Texas (Figure 1). These three sites are relatively close to each other and have similar geological settings, and all have had significant oil/gas extraction and fluid injection operations. Time series InSAR (Interferometric Synthetic Aperture Radar) data are used to measure surface deformation and to estimate media properties and equivalent reservoir deformation (e.g., Shirzaei et al., 2019; Vasco et al., 2008, 2010, 2016; Yang et al., 2015). Coulomb failure stress changes were calculated to assess whether fault failure was promoted. These data and models allow us to gain some insight into relations between fluid injection/extraction, reservoir dynamics, and whether or not earthquakes have been induced above natural background levels.

\section{Geological Setting and Seismicity of Study Area}

The Permian basin is a large sedimentary basin in western Texas and southeastern New Mexico and is one of the most prolific oil and gas basins in the United States. The basin is made up of three parts. From west to east these are the Delaware Basin, the Central Basin Platform, and the Midland Basin. Most earthquakes in the past century in the Delaware Basin are likely induced, related to petroleum production (Frohlich et al., 2016).

Our three study sites are located in the eastern part of the Delaware Basin (Figure 1a). This is the thickest part of the basin with a depth of 6-7 km (Hills, 1984; Robinson, 1988). Based on the geological strata (Engle et al., 2016; Matchus \& Jones, 1984; Sinclair, 2007), we divide the basin into five layers (Table 1 and Figure 2a). From top to bottom these are (1) Post-Permian sediments and Ochoan evaporites; (2) the Delaware Mountain Group; (3) the Bone Spring formation, as well as other Permian, Mississippian, and Pennsylvanian age strata; (4) Ordovician, Silurian, and Devonian age strata; and (5) Precambrian basement. Most injection wells in our study area inject into the Delaware Mountain Group (Figure 2a). The sandstone in this layer helps fluid diffuse relatively quickly, in principle minimizing large pore pressure buildup. Most production wells are in the layer below (Figure 2a). The main rock type of the production layer is shale, which has relatively low hydraulic conductivity, diffusing fluids much slower than the upper layer. 

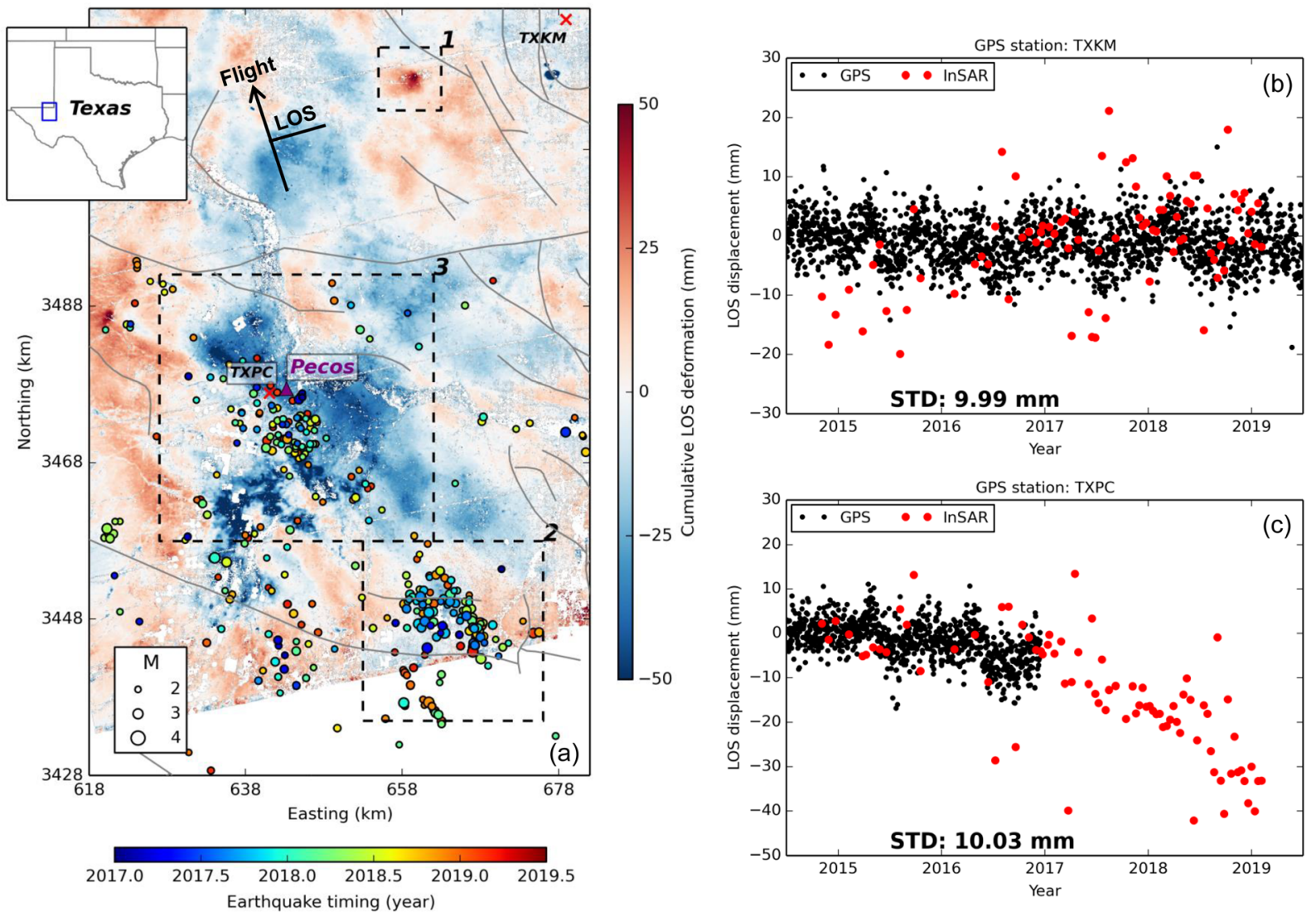

Figure 1. (a) Location map of study area. The base map is cumulative InSAR line-of-sight (LOS) deformation from 4 November 2014 to 5 February 2019 using Sentinel-1 SAR data. Radar flight and LOS orientations are indicated by black arrows. Positive values (warm color) means motion toward the satellite; negative values (cold color) means motion away from the satellite. Colored circles indicate the location and time of earthquakes with magnitude $\geq 2.0$, provided by the TexNet Earthquake Catalog. Dashed boxes show the three study sites. Purple triangle shows the location of Pecos city. Site 1 has obvious surface uplift but no earthquakes. Site 2 has slight surface subsidence but significant earthquake activity. Site 3 has obvious surface subsidence and also earthquake activity. Gray lines show faults from Ruppel et al. (2005). Red crosses are two GPS stations. (b and c) The comparison between the GPS (black dots) and InSAR (red dots) time series. The GPS measurements with three components (easting, northing, and up) were converted to radar LOS direction. The InSAR time series was shifted to match the GPS time series by the mean value of their difference. Standard deviation (STD) of difference between InSAR and GPS observations are labeled. Note that data of station TXPC is not available after year 2017. GPS data were downloaded from the Nevada Geodetic Laboratory (http://geodesy.unr.edu/).

Table 1

Simplified Vertical Structure of the Eastern Delaware Basin (Engle et al., 2016; Matchus \& Jones, 1984; Sinclair, 2007) and Hydraulic Parameters Used in This Study

\begin{tabular}{|c|c|c|c|c|c|c|c|}
\hline \multicolumn{2}{|c|}{ Layer depth $(\mathrm{km})$} & Main rock type & $K(\mathrm{~m} / \mathrm{s})$ & $S_{s}\left(\mathrm{~m}^{-1}\right)$ & $D\left(\mathrm{~m}^{2} / \mathrm{s}\right)$ & $B$ & Relative ease of transporting fluid \\
\hline $0.0-1.5$ & Site 1 & Halite, Andydrite & $2 \times 10^{-8}$ & $\begin{array}{l}4 \times 10^{-7} \\
1 \times 10^{-7}\end{array}$ & 0.05 & 6.5 & Medium \\
\hline $1.5-2.7$ & $\begin{array}{c}\text { Site } 1 \\
\text { Sites } 2 \text { and } 3\end{array}$ & Sandstone & $\begin{array}{l}2 \times 10^{-8} \\
1 \times 10^{-7}\end{array}$ & $\begin{array}{l}4 \times 10^{-7} \\
1 \times 10^{-7}\end{array}$ & $\begin{array}{c}0.01 \\
0.05 \\
1.0\end{array}$ & $\begin{array}{l}0.9 \\
6.5 \\
0.9\end{array}$ & High \\
\hline $2.7-5.5$ & Sites 1,2 , and 3 & Shale & $1 \times 10^{-9}$ & $1 \times 10^{-8}$ & 0.1 & 0.9 & Medium \\
\hline $5.5-6.5$ & Sites 1,2 , and 3 & Limestone & $1 \times 10^{-8}$ & $1 \times 10^{-7}$ & 0.1 & 0.9 & High \\
\hline$>6.5$ & Sites 1,2 , and 3 & Basement & $1 \times 10^{-10}$ & $1 \times 10^{-8}$ & 0.01 & 0.9 & Low \\
\hline
\end{tabular}

Note. $K$ is hydraulic conductivity, $S_{S}$ is specific storage, $D$ is hydraulic diffusivity, $B$ is Skempton ratio. The last column indicates the relative ease of fluid transport in each layer. 


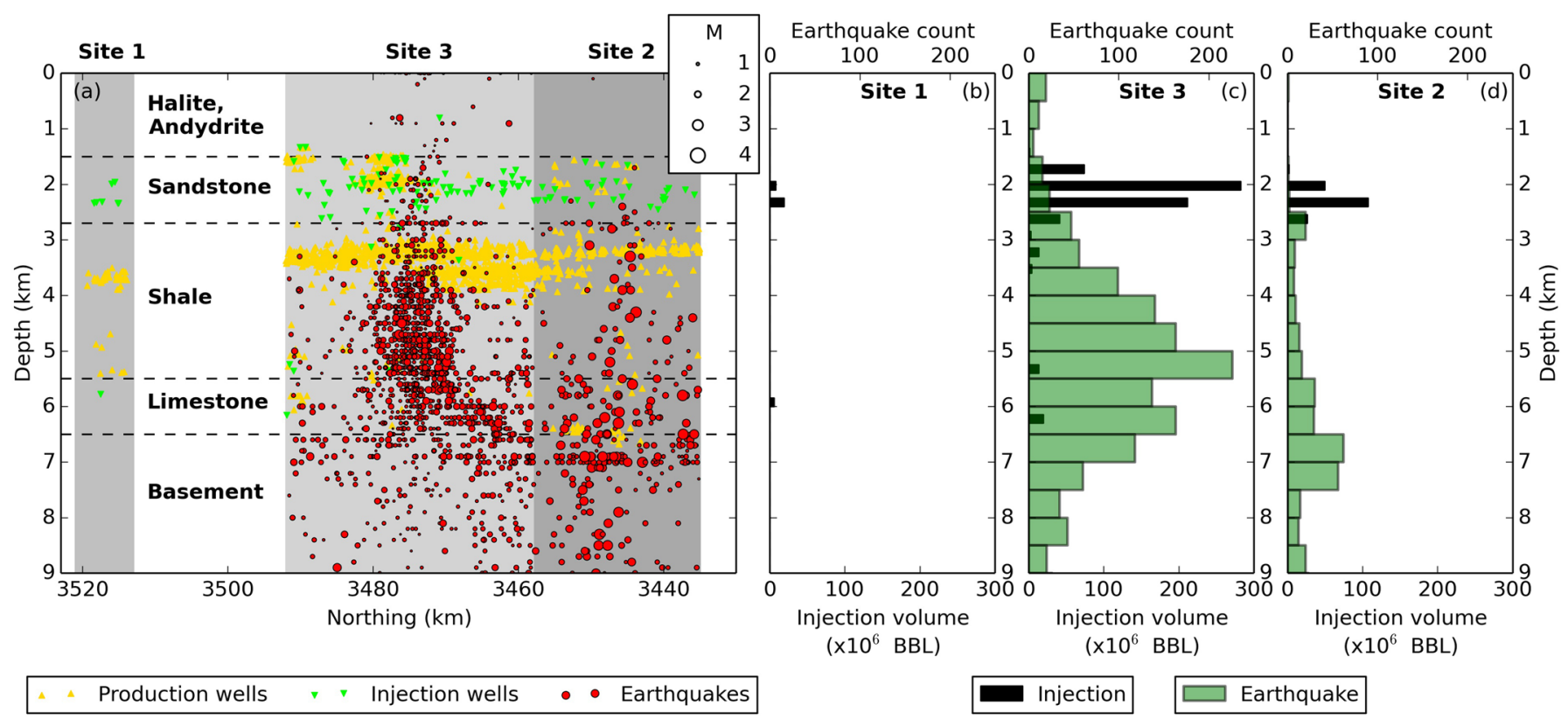

Figure 2. (a) Depth distribution of production wells (yellow triangles) injection wells (green triangles), and earthquakes (red dots) at our three study sites (highlighted in gray). The five model layers (Table 1) are labeled. (b, c, and d) Depth histograms of earthquakes (green bars) and fluid injection volume from 2007 to early 2019 (black bars) at Sites 1, 3, and 2, respectively. Earthquakes from the TexNet catalog with magnitude $\geq 0$ from January 2017 to March 2019 are used. Note that panel order on the right-hand side matches the geographic order of the left-hand side.

According to the USGS (United States Geological Survey) ANSS (Advanced National Seismic System) earthquake catalog, no earthquakes were reported before 2010 at any of our three study sites. Earthquake rates at Sites 2 and 3 increased dramatically in the past several years (Figures 3b-3e). The recent increase in seismicity resulted in a significant expansion of the seismic networks, lowering the magnitude of completeness and improving location precision relative to the USGS ANSS catalog (Savvaidis et al., 2019; supporting information Figure S1). We use the local earthquake catalog provided by TexNet (Savvaidis et al., 2019) for our seismicity analysis. The TexNet earthquake catalog is available from January 2017. A relocated version of these data is also available (Lomax \& Savvaidis, 2019). However, their relocation is based on the assumption that the seismicity is more likely due to hydraulic fracturing than saltwater disposal. To avoid biasing our results, we use the original data. The earthquakes from the TexNet catalog show similar spatial distribution pattern when magnitude threshold is 0 and 2 (Figures 1a, 2, S2, and S3). To reduce calculation burden, unless otherwise noted, the earthquakes used below are from the TexNet catalog with magnitude $\geq 2.0$ from January 2017 to March 2019.

Oil and gas production has also been increasing in the past several years, accompanied by increasing rates of underground fluid injection (Figures 3a-3c). The total number of earthquakes in a given region (Sites 1, 2, and 3) shows a positive relation with the total injection volume (Figures $2 \mathrm{~b}-2 \mathrm{~d}$ ). The spatial and temporal coincidence between the earthquakes and oil and gas production suggests the latter may be the cause for the earthquakes (Skoumal et al., 2020).

\section{Methods}

\subsection{InSAR Time Series Processing}

ALOS (January 2007 to March 2011, path 190 frame 610) and Sentinel-1 A/B (November 2014 to February 2019, path 78 frames 99-100) SAR (Synthetic Aperture Radar) data were used for surface deformation measurement and were processed separately. The Small Baseline Subset (SBAS) method (Berardino et al., 2002) was used to generate InSAR line-of-sight (LOS) time series. The GMTSAR software (Sandwell et al., 2011a, 2011b) was used for interferogram generation, phase unwrapping, and georeferencing. Thirty-meter SRTM (Shuttle Radar Topography Mission, Farr et al., 2007) digital elevation model (DEM) was used to remove topographic effects. The GIAnT software (Agram et al., 2013, 2016) was 

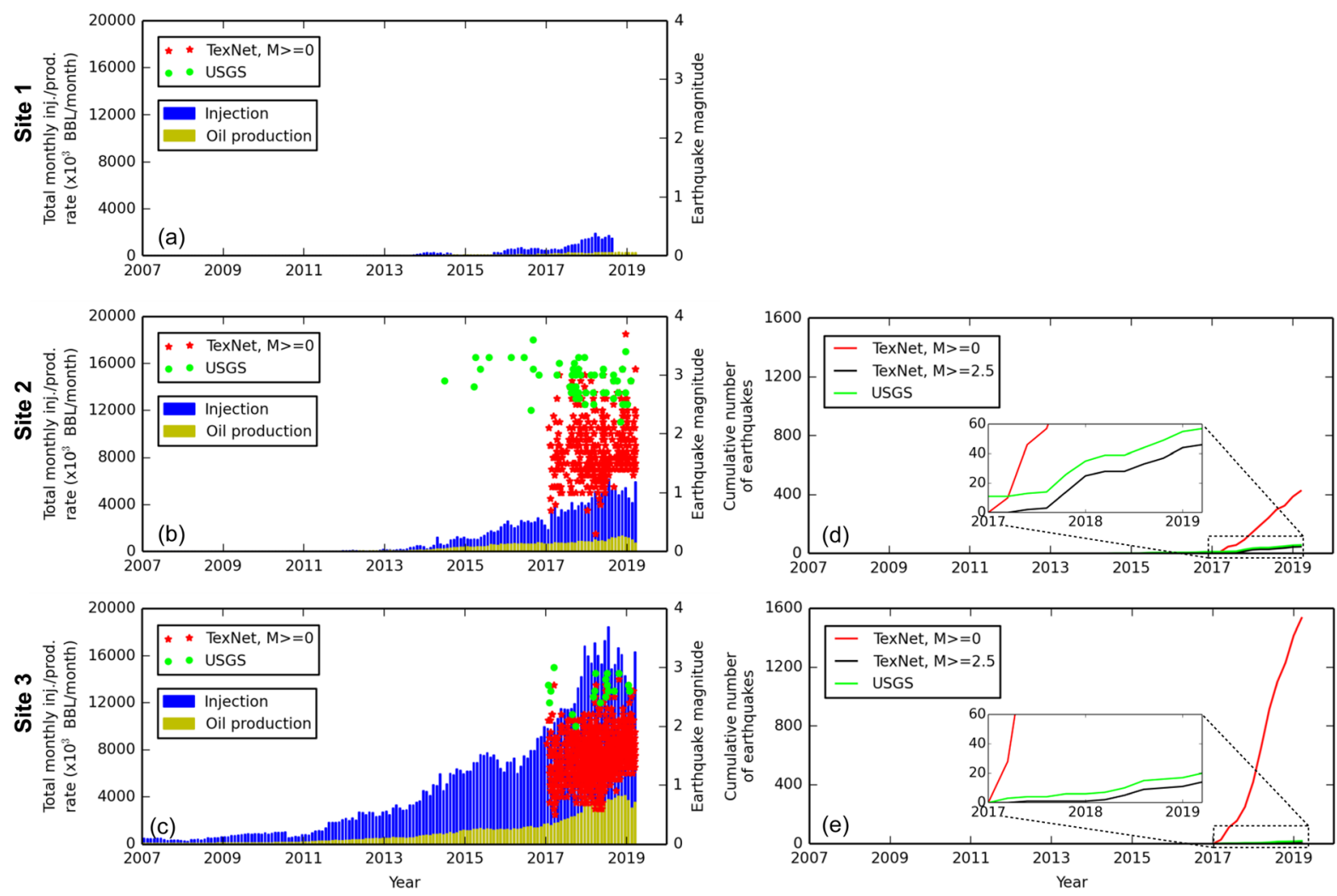

Figure 3. Total monthly fluid injection rate, oil production rate, and earthquake occurrence (a-c) and the cumulative number of earthquakes (d, e) for Sites 1 (a), 2 (b, d), and 3 (c, e). Note that Site 1 has no earthquakes. Earthquakes from both the TexNet and USGS ANSS catalogs are shown. The USGS catalog is roughly complete at $M \geq 2.5$ (note the similar trend of the green and black lines in $\mathrm{d}$ and e) but contains almost no smaller events. The TexNet catalog has a lower magnitude threshold ( 1.5; Savvaidis et al., 2019). The gas production rates have very similar trend to the oil production rates and are not plotted here. BBL means barrels $\left(1\right.$ barrel $\left.=0.159 \mathrm{~m}^{3}\right)$ of saltwater/oil calculated at $60^{\circ} \mathrm{F}\left(15.56^{\circ} \mathrm{C}\right)$. In this study oil production means crude oil produced from oil wells and condensate (hydrocarbon liquid) produced from gas wells. Gas production means gas produced from oil and gas wells. The injection data at Site 1 were not updated by publication time.

used to reduce the tropospheric effect using the ECMWF weather model and to generate deformation time series. Two GPS (Global Positioning System) stations (Blewitt et al., 2018) are available around our study area (Figure 1a). The standard deviation of difference between the InSAR time series and the correspondingly closest GPS measurements is $\sim 1 \mathrm{~cm}$ (Figures $1 \mathrm{~b}$ and 1c).

\subsection{Modeling of Pore Pressure Change and Deformation}

We assume the media have both porous and elastic properties. Depending on the study site, either these properties were considered together (poroelastic), or only one was considered, depending on reservoir behaviors, assumptions, and calculation burdens, as described below.

\subsubsection{Coupled Modeling of Pore Pressure Change and Deformation in Poroelastic Media}

In poroelastic theory, the governing equations relating displacement $\boldsymbol{u}$ and pore pressure change $p$ are (from Wang \& Kümpel, 2003; Zhai \& Shirzaei, 2018)

$$
\begin{aligned}
& G \nabla \cdot \nabla \boldsymbol{u}+\frac{G}{1-2 v} \nabla(\nabla \cdot \boldsymbol{u})-\alpha \nabla p=\boldsymbol{f}(\boldsymbol{x}, t) \\
& Q^{-1} \frac{\partial p}{\partial t}+\alpha \frac{\partial(\nabla \cdot \boldsymbol{u})}{\partial t}-\nabla \cdot(\chi \nabla p)=q(\boldsymbol{x}, t)
\end{aligned}
$$

where $G$ is shear modulus, $v$ is drained Poisson ratio, $\alpha$ is Biot effective stress coefficient, $Q^{-1}$ is bulk compressibility (Biot modulus), $\chi$ is Darcy conductivity (note that this differs from hydraulic conductivity $K$ ), $\boldsymbol{f}$ is the body force per unit volume acting on the solid matrix, and $q$ is the fluid volume injection/extraction rate. $\boldsymbol{f}$ and $q$ are functions of spatial position $\boldsymbol{x}$ and time $t$. 
We use the numerical solution provided by Wang and Kümpel (2003) to solve the above coupled poroelastic model and calculate the transient pore pressure change and deformation in a multilayer poroelastic half space due to fluid injection/extraction of a point source. Five independent parameters, $G, v$, undrained Poisson ratio $v_{u}$, hydraulic diffusivity $D$, and Skempton coefficient $B$, are needed for the calculation. Other parameters in equations 1 and 2 can be determined using these five parameters (Kümpel, 1991; Wang \& Kümpel, 2003).

\subsubsection{Modeling of Pore Pressure Change Without Considering Deformation in Porous Media}

The calculation burden of the above coupled model can be very high when there are hundreds to thousands of inputs (injection/extraction wells) and outputs (simulated pore pressure change and deformation at earthquake hypocenters). When deformation is relatively small or could not be well explained by point sources, we calculate only the pore pressure change using the MODFLOW-2005 software (Bakker et al., 2016; Harbaugh, 2005) without considering deformation. MODFLOW is the USGS's modular finite-difference hydrologic model. It is commonly used for pore pressure simulation due to its flexibility and speed (e.g., Zhang et al., 2013, 2016; Keranen et al., 2014; Hornbach et al., 2015; Ogwari \& Horton, 2016; Ogwari et al., 2018; Brown et al., 2017; Brown \& Ge, 2018; Goebel et al., 2017; Nakai et al., 2017; Hearn et al., 2018). It solves the three-dimensional movement of ground water of constant density in heterogenous and anisotropic porous media (from Harbaugh, 2005):

$$
\frac{\partial}{\partial x}\left(K_{x x} \frac{\partial h}{\partial x}\right)+\frac{\partial}{\partial y}\left(K_{y y} \frac{\partial h}{\partial y}\right)+\frac{\partial}{\partial z}\left(K_{z z} \frac{\partial h}{\partial z}\right)+W=S_{s} \frac{\partial h}{\partial t}
$$

where $K_{x x}, K_{y y}$, and $K_{z z}$ are the principal components of hydraulic conductivity, $S_{s}$ is the specific storage, $W$ is the volumetric flux per unit volume representing sources of fluid, $h$ is hydraulic head, and $t$ is time. In general, $S_{s}, K_{x x}, K_{y y}$, and $K_{z z}$ are functions of space, and $W$ is a function of space and time. Hydraulic head change can be converted to pore pressure change by

$$
p=\rho g \Delta h
$$

where $\rho$ is the density of the fluid, and $g$ is the gravitational acceleration. $\rho$ is set to $1,000 \mathrm{~kg} / \mathrm{m}^{3}$ in our model. Multilayer heterogenous and isotropic (i.e., $K_{x x}=K_{y y}=K_{z z}$ ) media are used in our MODFLOW model (Table 1). Hydraulic conductivity $K$ is related to hydraulic diffusivity $D$ and specific storage $S_{S}$ by the relation

$$
K=D S_{S}
$$

Deformation is not considered in MODFLOW. We have tested that for a point source causing relatively small surface deformation ( $<5 \mathrm{~mm}$ in our case), the simulated pore pressure changes using MODFLOW and the coupled poroelastic model (Wang \& Kümpel, 2003) have the same order of magnitude (Figure 6c).

\subsubsection{Modeling of Deformation in Elastic Media}

Publicly available data about the geometry and physical, chemical, and thermal properties of the reservoirs in our study area are limited. When the observed InSAR deformation could not be well explained by fluid injection/extraction due to point sources (e.g., surface deformation due to a point source should have a simple radial pattern), we consider the simpler elastic case by imagining a finite reservoir embedded in an elastic medium. We use the Okada solution (Okada, 1992) to model the equivalent source strength, which causes the same magnitude of surface deformation as the real complex source. This is a simplified process; the inverted source does not necessarily have a physical relation to the real reservoir.

Horizontal Okada patches with uniform grid size are placed at the average depth of production (for surface subsidence) or injection (for surface uplift) wells. The observed surface deformation is assumed to be caused by the Okada tensile dislocation (perpendicular to the Okada patches). The tensile dislocation of each Okada patch is inverted by best fitting the observed InSAR deformation. The InSAR observation in the target area is down-sampled to points with $0.5 \mathrm{~km}$ by $0.5 \mathrm{~km}$ interval. Points with $1 \mathrm{~km}$ by $1 \mathrm{~km}$ interval with a deformation value of 0 were added as background observations beyond the target area to avoid edge effects. A Gaussian filter with a window size of 0.3 years is used to filter the InSAR time series for every pixel/location (Figure S4a). A smoothness constraint (Tikhonov regularization) is applied to the 
inversion to make sure that the inverted tensile dislocation of each patch does not change abruptly compared to adjacent patches (Menke, 2018). A simple L curve is used to find the best trade-off between smoothness and misfit (Hansen, 1999) (Figure S4b). For each time slice of the SAR data, we apply the above inversion to solve for the tensile dislocation of every patch relative to the first time slice (taken as the reference, deformation is 0). Similar Okada tensile models have been used to invert the source dynamics (e.g., volumetric strain) based on surface deformation due to fluid withdrawal (Mossop \& Segall, 1999) and injection (Kim \& Lu, 2018; Shirzaei et al., 2016).

Some studies suggest that the homogeneous assumption can result in inaccurate estimates of the source strength (e.g., Hearn \& Bürgmann, 2005; Vasco et al., 2010). Our assumed source has a simple geometry, a horizontal plane with pure tensile deformation. Numerical tests with this source using the homogenous Okada model show that the calculated deformation is not very sensitive to values of the shear modulus or Poisson's ratio within reasonable limits (Figure S5). Since knowledge of the media properties in the study area is limited, we opted to use the simplified approach described above. The calculated Coulomb stress change due to our assumed source using the homogeneous and heterogeneous models should have the same order of magnitude unless the elastic parameters differ significantly. Moreover, the sign of the Coulomb stress change will not be affected. Hence, the homogeneous Okada model is adequate for the purposes of our study: (1) to determine whether failure is promoted at faults, that is, whether the sign of the Coulomb stress change is positive); and (2) to determine the main contributor to abnormal earthquakes, Coulomb stress change due to reservoir compaction (oil/gas extraction) or pore pressure increase due to fluid injection. The order of magnitude of the calculated stress/pressure change rather than the exact value is sufficient for these determinations.

\subsection{Coulomb Failure Stress Calculation}

We calculate the Coulomb failure stress (CFS) change at the time and hypocenter of a certain earthquake to assess if the earthquake is likely induced or not. Considering the effect of pore pressure change, the CFS change $\Delta \tau$ is (e.g., Zhai \& Shirzaei, 2018)

$$
\Delta \tau=\Delta \tau_{\mathrm{s}}+\mu\left(\Delta \sigma_{\mathrm{n}}+p\right)=\left(\Delta \tau_{\mathrm{s}}+\mu \Delta \sigma_{\mathrm{n}}\right)+\mu p
$$

where $\Delta \tau_{\mathrm{s}}$ is the change in shear stress (positive when sheared in the direction of fault slip), $\Delta \sigma_{\mathrm{n}}$ is the change in normal stress (positive if the fault is unclamped), $\mu$ is the coefficient of friction on the fault, and $p$ is the pore pressure change (positive when pore pressure increases). The presence of excess pore pressure decreases the effective normal stress, bringing the fault closer to failure. Positive CFS change favors fault slip.

To calculate CFS change due to the tensile dislocation of Okada patches, the software Coulomb 3.3 (Lin \& Stein, 2004; Toda et al., 2005, 2011) was used. The input parameters for Coulomb 3.3 include the size, location and dislocation of each Okada patch, Poisson's ratio, Young's Modulus, friction coefficient, and location and orientation of receiving faults. We calculate $\Delta \tau_{\mathrm{s}}+\mu \Delta \sigma_{\mathrm{n}}$ (the CFS change without the part of pore pressure change) at each earthquake hypocenter for all SAR slices based on the inverted Okada patch dislocations. The calculated stress change of the slice whose timing is closest to the time of a certain earthquake is taken as the stress change for that earthquake. For every earthquake, $\Delta \tau_{\mathrm{s}}+\mu \Delta \sigma_{\mathrm{n}}$ due to all orientations (different combinations of strike, dip, and rake angles of a fault) in $5^{\circ}$ intervals is calculated.

\section{Results}

The main results of our study are summarized in Table 2 and described below.

\subsection{Site 1}

Produced water during oil and gas extraction is usually injected underground for disposal. At Site 1, surface uplift was observed around several injection wells (Figure 4a). The injection depth of most wells is $\sim 2 \mathrm{~km}$ below the land surface (BLS) (Figure 2a). The maximum cumulative surface deformation happens at the well with the maximum injection volume and rate (Figure 4a). The trends in the deformation time series match very well with the monthly injection rate (Figure $4 \mathrm{~b}$ ), suggesting that the observed surface deformation is likely caused by this well. Surface uplift was observed after injection started. Uplift rate decreases and even turns negative when injection rate decreases. Note the several-month delay in the 
Table 2

Deformation, Earthquakes, and Their Likely Causes and Modeling Schemes at Our Three Study Sites

\begin{tabular}{|c|c|c|c|c|c|c|c|}
\hline \multicolumn{2}{|c|}{ Site \# } & Activity & $\begin{array}{c}\text { Surface } \\
\text { deformation }\end{array}$ & Earthquakes & $\begin{array}{l}\text { Main reason } \\
\text { for deformation }\end{array}$ & $\begin{array}{c}\text { Main reason } \\
\text { for earthquakes }\end{array}$ & Modeling scheme \\
\hline \multicolumn{2}{|l|}{1} & \multirow{4}{*}{$\begin{array}{c}\text { Fluid injection, } \\
\text { oil and gas } \\
\text { extraction at all } 3 \text { sites }\end{array}$} & Uplift & No & Fluid injection & $\mathrm{N} / \mathrm{A}$ & $\begin{array}{l}\text { Coupled poroelastic model } \\
\text { (Wang \& Kümpel, 2003) }\end{array}$ \\
\hline 2 & & & Slight subsidence & Yes & $\begin{array}{c}\text { Groundwater } \\
\text { withdrawal }\end{array}$ & Fluid injection & MODFLOW \\
\hline \multirow[t]{2}{*}{3} & North & & & & Gas extraction & Fluid injection & MODFLOW, Okada (1992) \\
\hline & South & & Subsidence & Yes & $\begin{array}{l}\text { Groundwater } \\
\text { withdrawal }\end{array}$ & N/A & N/A \\
\hline
\end{tabular}

Note. "N/A" means "not applicable."

appearance of the local minimum and maximum in the InSAR time series compared to the changes of the injection rate (Figure $4 \mathrm{~b}$ ). The spatial and temporal agreement suggests that the surface uplift is caused by the fluid injection.

We modeled the surface deformation and pore pressure change at the well with the maximum injection volume using a multilayer (five-layer) model (Matchus \& Jones, 1984; Engle et al., 2016; Sinclair, 2007;
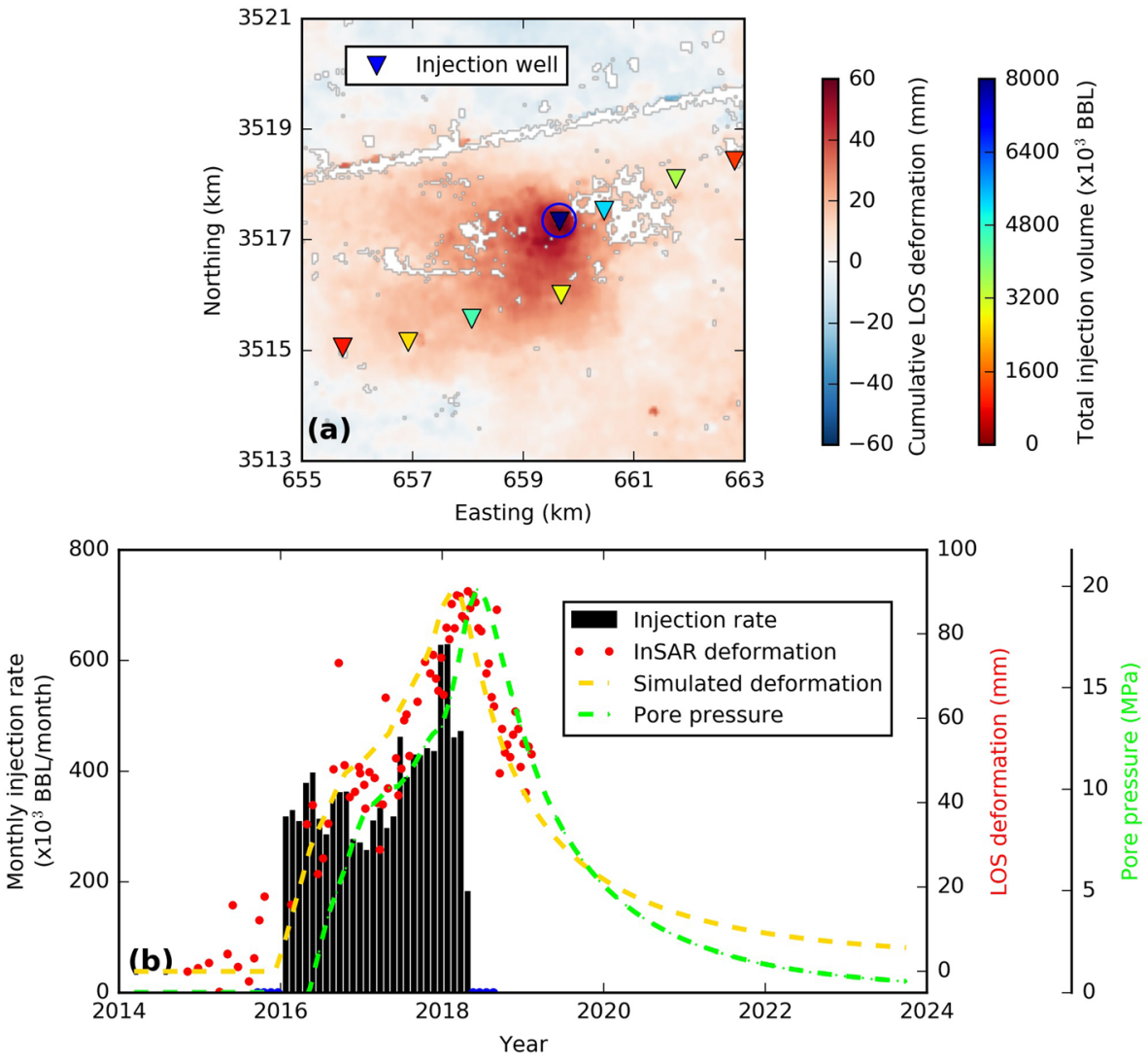

Figure 4. Comparison between observed surface deformation, injection rate, simulated surface deformation, and simulated surface pore pressure at Site 1 (Figure 1a). (a) Zoomed-in view of cumulative InSAR (Sentinel-1) LOS surface deformation from 4 November 2014 to 5 February 2019. Injection wells and their accumulated injection volume are shown with colored triangles. The maximum surface deformation happens at the well with the maximum injection volume (circled). Note that no seismicity is reported at this site by the time of this study. (b) Time series of InSAR LOS deformation (red circles) and available monthly injection rate (black bars, from the Railroad Commission of Texas [Texas RRC]) at the injection well with the maximum injection volume. Blue dots on the horizontal axes indicate an injection rate of 0 , which is used to distinguish 0 from nonavailable data (void value). Yellow and green lines are simulated surface LOS deformation and surface pore pressure changes at the location of the well with the best fit hydraulic parameters for Model Layers 1 and 2 (Table 1), which allow the simulated deformation to match the trends and magnitude of the observed InSAR deformation. 

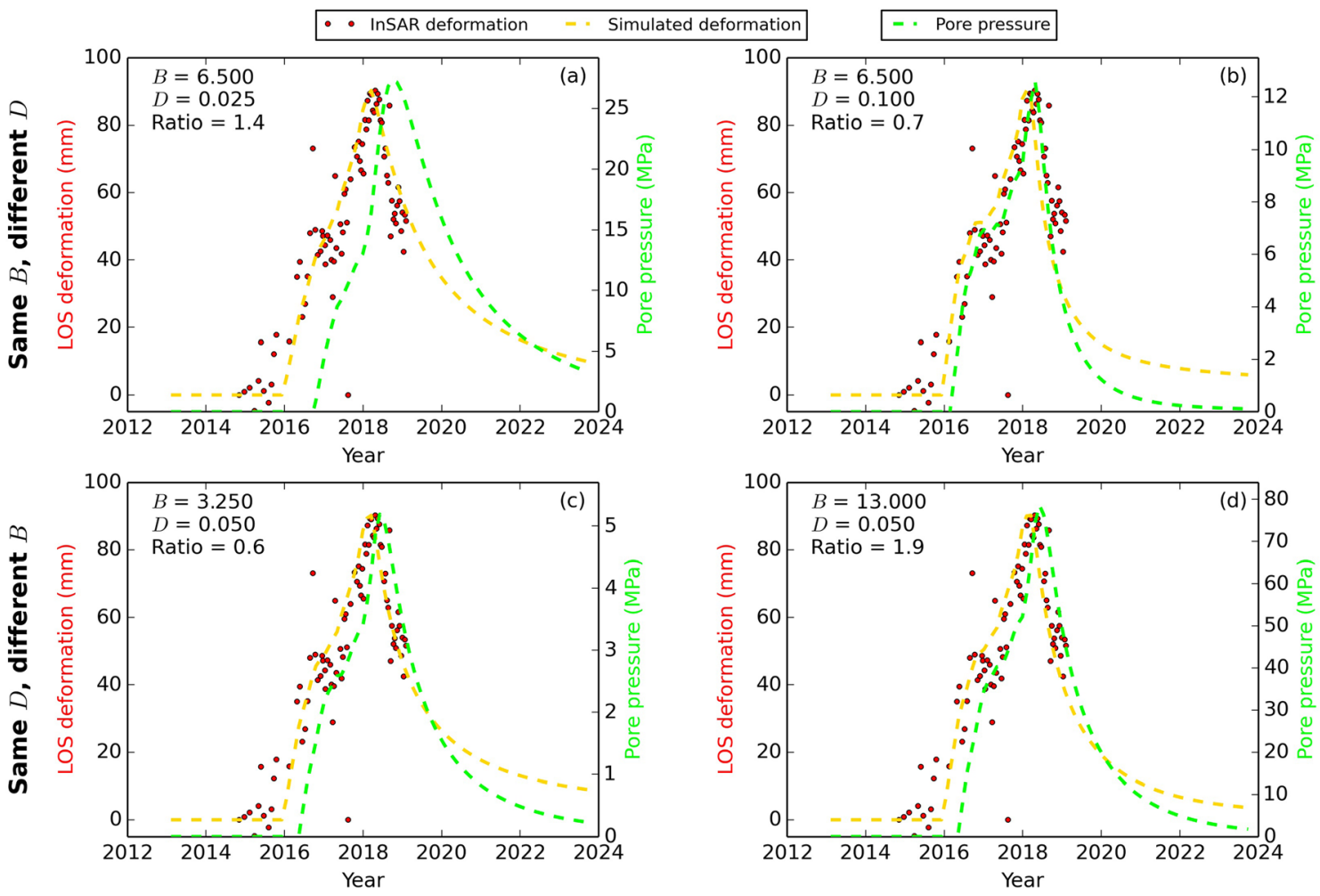

Figure 5. Sensitivity analysis of hydraulic diffusivity $D\left(\mathrm{~m}^{2} / \mathrm{s}\right)$ and Skempton ratio $B$ (unitless) in Layers 1 and 2 using the coupled poroelastic model (Wang \& Kümpel, 2003) at Site 1 (Figure 4b). The simulated surface deformation was scaled to the observed InSAR deformation by a ratio (the maximum simulated deformation divided by the maximum observed deformation) for trend comparison. $D$ affects both the trend and magnitude of the simulated deformation (a, b). B only affects the magnitude (c, d). The green lines are the simulated surface pore pressure changes.

Table 1) assuming poroelastic behavior. The numerical solution to the coupled model developed by Wang and Kümpel (2003) was used for the calculation. Only the injection activity of the well with the maximum injection rate and volume is considered. Contribution to the surface deformation from adjacent wells is considered to be small (Figure S6).

While our model agrees closely with the observations (Figure 4b), the result is sensitive to assumed values of rock properties. These can be constrained in a relative sense based on laboratory values for rock types in the different stratigraphic layers (Table 1, Duffield, 2019). We fix the parameters for Layers 3-5 (the layers below the injection layer) and adjust parameters for other layers. Shear modulus and drained and undrained Poisson's ratios are set to $2 \times 10^{10} \mathrm{~Pa}, 0.25$, and 0.45 , respectively, for all layers. For Site 1 , we treat Layers 1 and 2 as a single layer and consider their average effect in the model.

The parameter values of hydraulic diffusivity $D$ and Skempton ratio $B$ are estimated by inverting to match trends and magnitudes in the observed InSAR time series. When using different values for $D$ and $B$, we notice that $D$ affects both the trend (slope of the curve) and magnitude of the simulated deformation time series (Figures $5 \mathrm{a}$ and $5 \mathrm{~b}$ ), while $B$ only affects the magnitude (Figures $5 \mathrm{c}$ and $5 \mathrm{~d}$ ). With a smaller $D$, the simulated deformation is larger and has a longer time lag corresponding to the change of injection rate. The final value for $D\left(0.05 \mathrm{~m}^{2} / \mathrm{s}\right)$ was determined by matching the trend of the InSAR time series judged by eye. We then ran the model multiple times using different values for $B$. The final value for $B(6.5)$ was the one that best matched the maximum simulated deformation and maximum observed deformation in the time series.

The simulated pore pressure changes show a slower response to changes in the injection rate compared to the simulated deformation (Figure 4b). The elastic interaction due to fluid injection or withdrawal is instantaneous, while the transport of pore fluid due to pore pressure change follows the diffusion law and is 

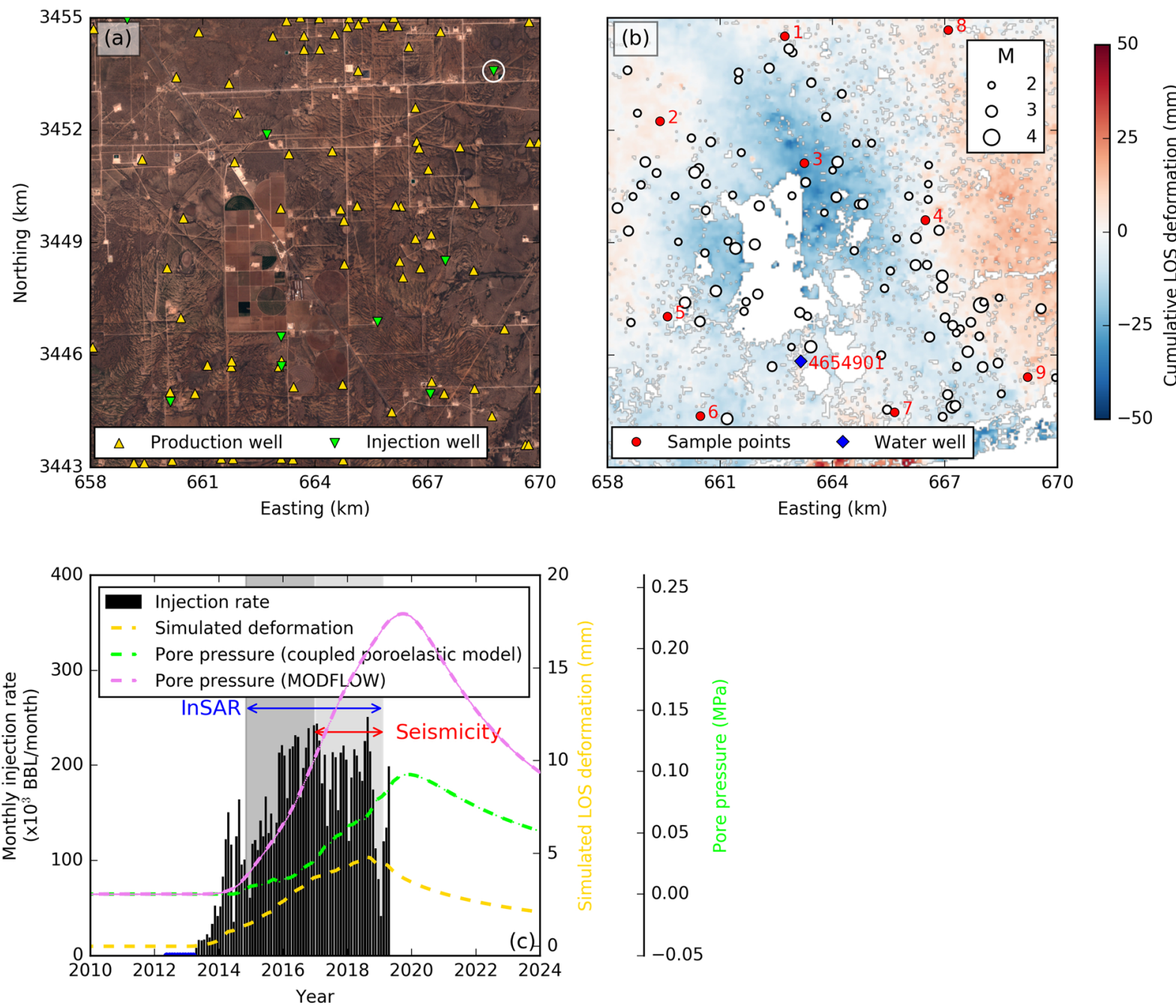

Figure 6. (a) Sentinel-2 optical image acquired on 25 February 2019 of Site 2. Yellow and green triangles show the location of production and injection wells. The white-circled well has the maximum injection volume in this area and is used in (c). (b) Cumulative surface LOS deformation from 4 November 2014 to 5 February 2019 using Sentinel-1 SAR data. Black circles show earthquake locations and magnitudes. Red dots show the locations of sample points used in Figure 7. Blue diamond shows the location of the groundwater well. The farm land causes data gap in the InSAR data due to low coherence. (c) Green and yellow lines are the simulated surface pore pressure change and surface deformation at the location of the well with the maximum injection volume in this area (the white-circled well in a) using the coupled poroelastic model (Wang \& Kümpel, 2003). The purple line is the simulated surface pore pressure change using the MODFLOW model. The temporal bounds of the InSAR time series and seismicity catalog used are indicated.

delayed (Wang \& Kümpel, 2003). Therefore, the poroelastic deformation has a time lag, and the time lag is shorter compared to the pore pressure change.

No earthquakes have been reported in this area at the time of this study. The calculated maximum pore pressure changes due to the well with the maximum injection volume at locations 1,3 , and $5 \mathrm{~km}$ away (vertical distance) from the injection location are 5.4, 0.4 , and $0.1 \mathrm{MPa}$, respectively. Although these values have the potential to induce earthquakes, no earthquakes are reported. No faults at depth are a possible explanation for the absence of earthquakes (no surface faults are mapped at this location). Other studies (e.g., Karegar et al., 2015; Shirzaei et al., 2016; Yang et al., 2015) also observed surface uplift due to fluid injection but no earthquakes close to the injection location. Further studies are needed to see if this phenomenon is a coincidence, and if not, what the geomechanical reasons are. Note, however, that total injected volume at this site is much lower compared to our other two study sites, where significant seismicity occurs (Figures 2 and 3). 

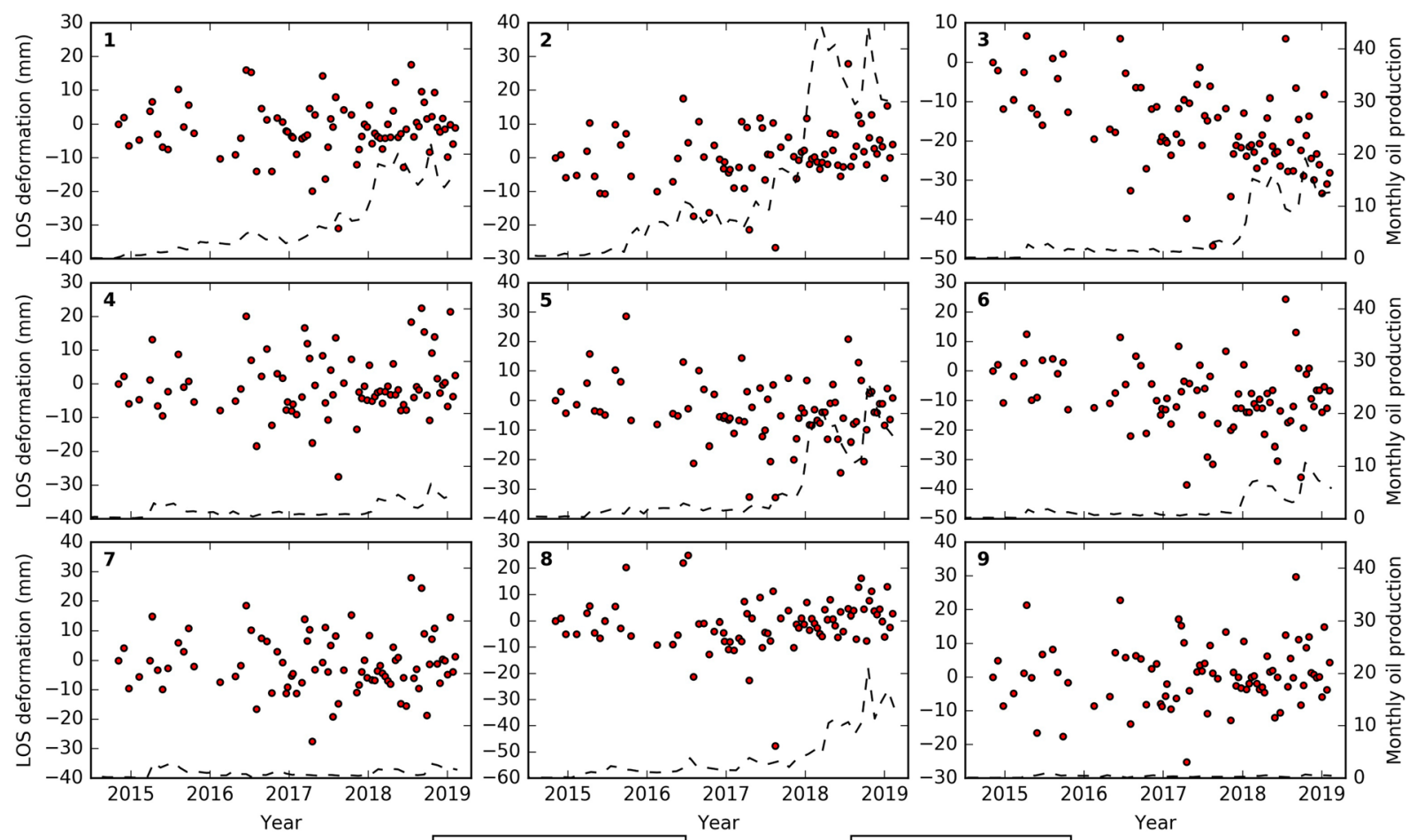

- InSAR, Sentinel-1

- - Oil production

Figure 7. Time series of Sentinel-1 InSAR LOS deformation and monthly oil relative production rates (Text S1; Scott, 2015) at sample points (Figure 6b) at Site 2. The monthly gas relative production rates have very similar trend (Figure S7) and are not plotted here.

\subsection{Site 2}

Surface subsidence was observed near agricultural land at Site 2 (Figures $6 \mathrm{a}$ and $6 \mathrm{~b}$ ). The subsidence occurred before increased oil and gas production (e.g., Sample Point 3 in Figures $6 \mathrm{~b}$ and 7), and the surface deformation rate was not affected by changes in the oil and gas production rate. Only one groundwater well with three water level measurements from Years 1988 to 2010 is available here (Figure 6b and Table S1). The measurements suggest that water level decreased $\sim 18 \mathrm{~m}$ during this period. Other areas at Site 2 do not show obvious surface deformation (e.g., Sample Points 1-2 and 4-9 in Figures 6b and 7). Hence, the observed surface subsidence is likely caused by groundwater withdrawal for irrigation instead of oil and gas production. Although some injection wells at Site 2 have similar magnitude of injection rate/volume to Site 1, no obvious surface uplift is observed.

Significant earthquake activity has been reported at Site 2 (Figures 1a, 3b, and 3d). To see whether this might be due to pore pressure changes associated with injection, we simulated the 3-D pore pressure change due to fluid injection at the time and hypocenter of earthquakes using MODFLOW. The model cell size is set to $0.5 \mathrm{~km}$ (length) by $0.5 \mathrm{~km}$ (width) by $0.1 \mathrm{~km}$ (depth). The model has five layers (Table 1). Its top and bottom depths are 0 and $10 \mathrm{~km}$, respectively. Well injection rate is assumed to be 0 after the last available data even though some injection activities may have continued. In addition to well injection location and rate, media properties, hydraulic conductivity $K$, and specific storage $S_{S}$ are essential inputs in the model. The temporal and spatial correlation between the fluid injection activity and earthquake occurrence suggests a scenario whereby earthquakes may be induced by pore pressure increases due to fluid injection (Skoumal et al., 2020). We assume that $0.1 \mathrm{MPa}$ ( 1 bar) excess pore pressure, an empirical value, is needed to induce earthquakes. Previous studies suggested that anthropogenic stress changes of $\sim 1$ bar are sufficient to trigger earthquakes (e.g., Hornbach et al., 2016; Hough et al., 2017; Keranen et al., 2014; Segall et al., 1994). Thresholds with similar magnitude are commonly suggested for natural and naturally triggered earthquakes (e.g., Reasenberg \& Simpson, 1992; Saar \& Manga, 2003; Stein, 1999). Other studies have suggested that stress change of $\sim 0.1$ bar or even smaller can also trigger earthquakes (e.g., Cochran et al., 2004; Hainzl et al., 2006). To reach 1 bar 
Site 2

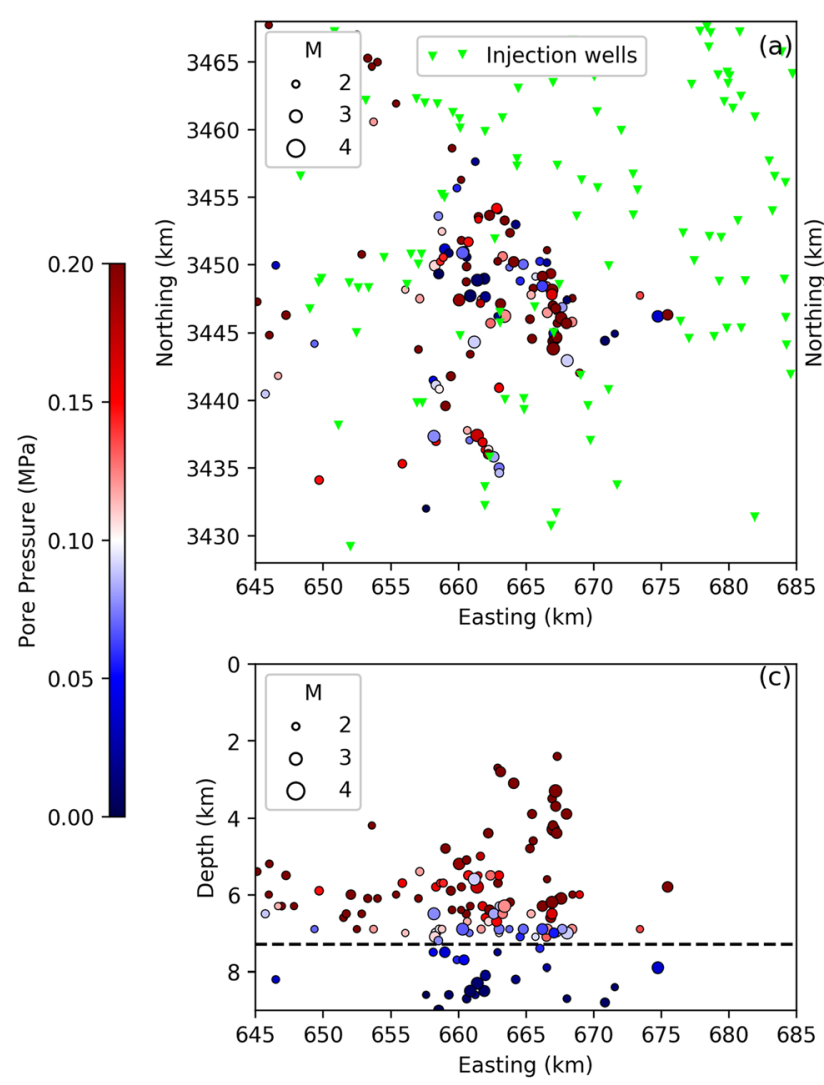

Site 3

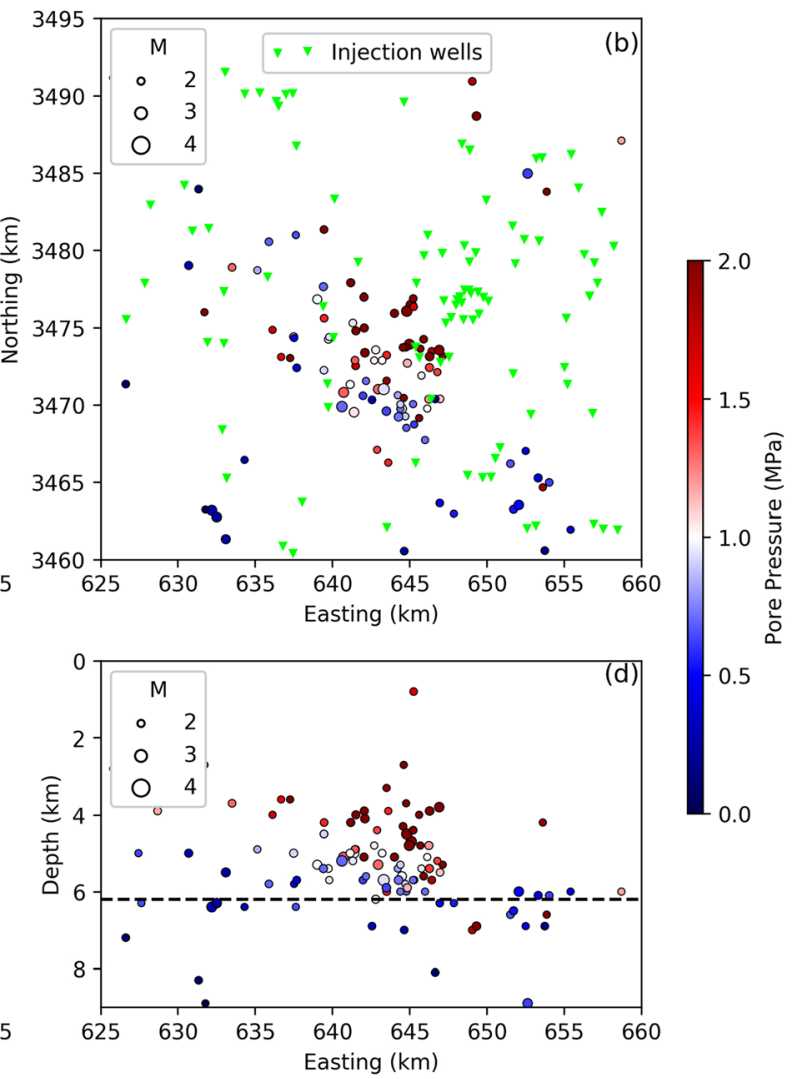

Figure 8. Simulated pore pressure changes at earthquake hypocenters (colored circles) due to fluid injection (green triangles) at Sites 2 (a, c) and 3 (b, d) using parameters in Table 1. Only earthquakes with magnitude $\geq 2.0$ and depth (BLS) $\leq 9 \mathrm{~km}$ are plotted. Dashed black lines in (c) and (d) indicate the approximate depth of the basin bottom (from Robinson, 1988). Note the different scales of color bars.

pore pressure change, we adjust the hydraulic parameters for Layers 1, 2, 4, and 5, while Layer 3 is fixed as the reference. The final parameters used in the model are given in Table 1.

MODFLOW does not consider deformation. To assess how the simulated pore pressure might be biased, we compared the simulated pore pressure changes due to the well with the maximum injection volume at Site 2 using both MODFLOW and the coupled poroelastic model (Wang \& Kümpel, 2003) (Figure 6c). Parameters in Table 1 were used. The poroelastic model suggests that the maximum surface uplift is $\sim 5 \mathrm{~mm}$ (Figure $6 \mathrm{c}$ ), similar to the level of noise in the InSAR data (Figures 1b, 1c, and 7). The simulated pore pressure changes using the above two models have the same order of magnitude. These suggest that our modeling scheme, using MODFLOW to simulate pore pressure changes in areas with no obvious surface deformation related with fluid injection, is acceptable.

In general, the closer an earthquake to the injection layer, the higher the simulated pore pressure change (Figures $8 \mathrm{c}$ and $8 \mathrm{~d}$ ). The simulated pore pressure changes at most earthquake hypocenters are $\sim 0.05$ to $0.3 \mathrm{MPa}$ ( 0.5 to 3 bars) at Site 2 (Figures $8 \mathrm{a}$ and $8 \mathrm{c}$ ). The adjusted values of the hydraulic parameters are reasonable for the range of rock types in this area (Table 1, Duffield, 2019), so the hypothesis that these earthquakes may be related to pore pressure changes associated with fluid injection is reasonable, though of course not proven.

\subsection{Site 3}

Significant surface subsidence was observed at Site 3 near the city of Pecos (Figures 9a and 9b). Ground subsidence over $200 \mathrm{~mm}$ was observed between 1935 and 1956 in the vicinity of Pecos using leveling data (Rosepiler \& Reilinger, 1977). Subsidence was accompanied by water level decreases in groundwater 

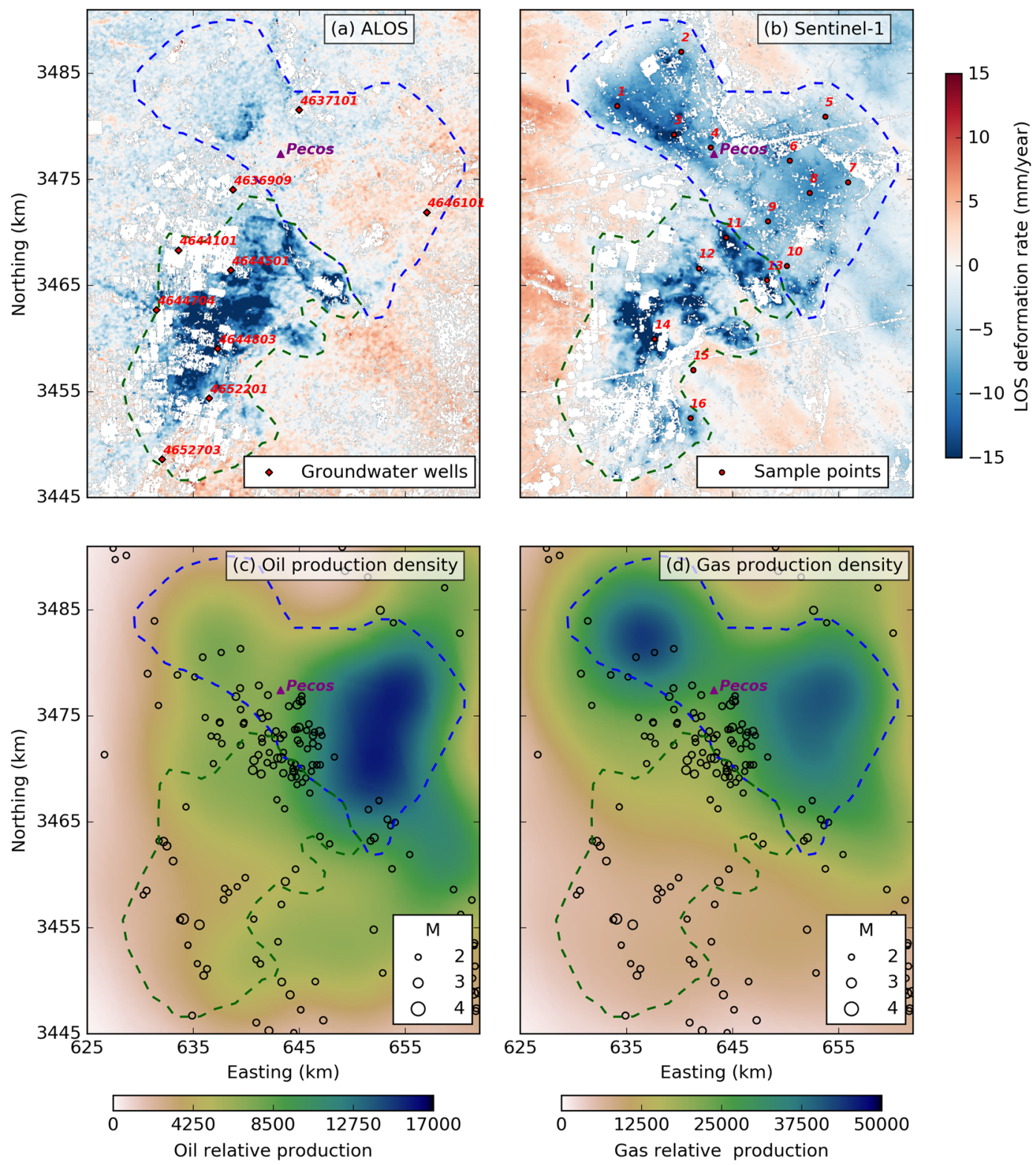

Figure 9. InSAR LOS deformation rate map calculated by fitting the time series using a simple linear model (a, b) and oil and gas relative production density map (c, d) at Site 3. ALOS data were used for the period January 2007 to March 2011 (a), and Sentinel-1 data were used for the period November 2014 to February 2019 (b). The blue and green dashed polygons show the extent of the northern and southern parts, respectively. (c and d) The relative production density map (Text S1; Scott, 2015) of the accumulated oil and gas production for the period of the Sentinel-1 data.

Black circles show earthquakes. Purple triangle shows the location of Pecos city.

wells, likely due to excessive groundwater withdrawal (Rosepiler \& Reilinger, 1977). Local water levels have partially rebounded since then (Boghici, 2008; Bruun et al., 2016), although continued declines have been observed at some wells, perhaps reflecting continued water withdrawals in some areas.

Oil and gas extraction increased dramatically in the past several years in this area (Figure 3c), which may also contribute to the observed surface subsidence. Combining InSAR deformation time series, water level observations (Figures 9a, 10, S8, and S9), and oil/gas production records, we can divide Site 3 into two parts: the northern part, where subsidence is likely related to oil and gas extraction, and the southern part, where ground water withdrawal is likely the main cause (Figure 9). Subsidence in the south was present in the 

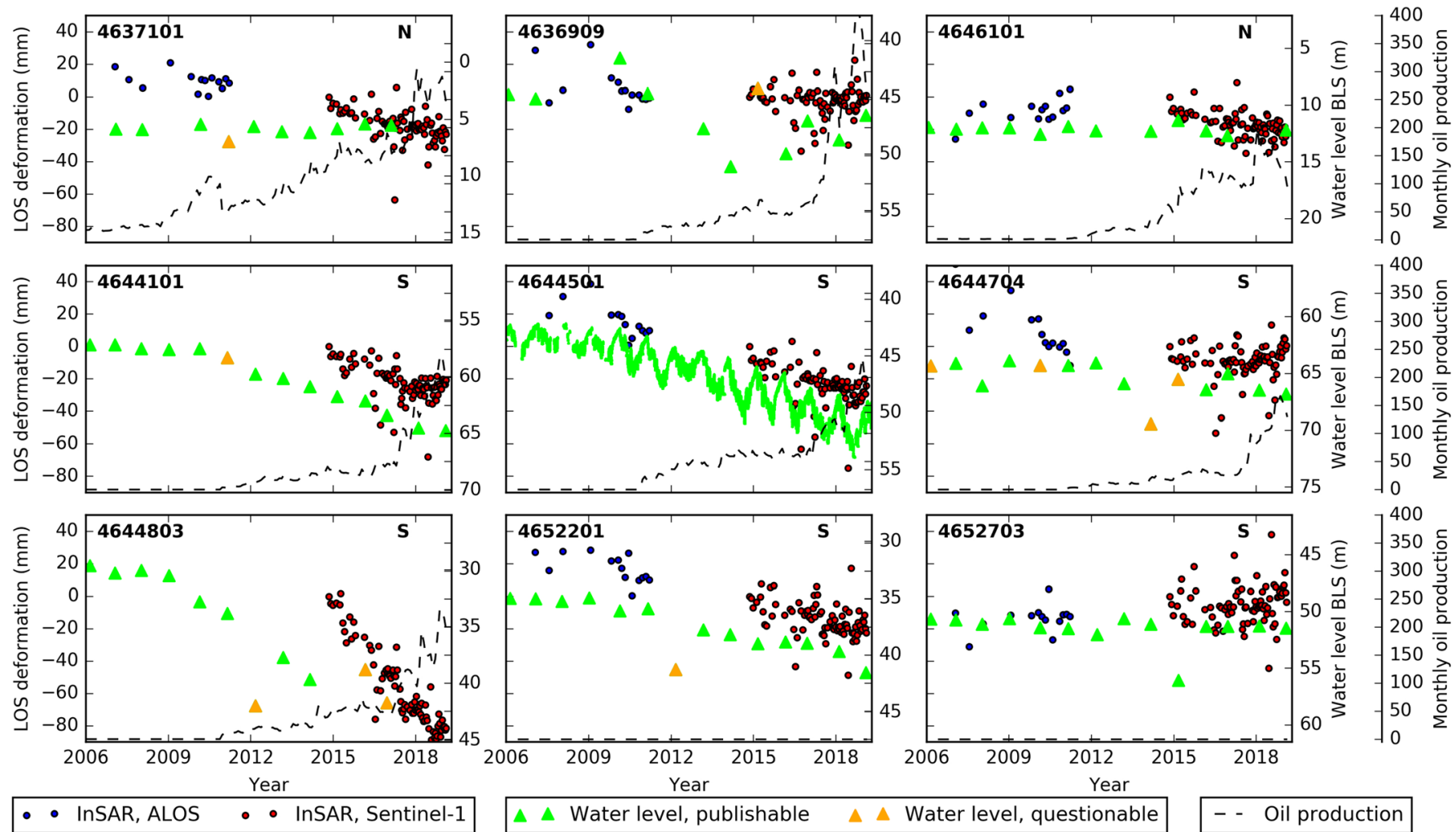

Figure 10. Time series of InSAR LOS deformation, ground water level (BLS) and monthly oil relative production rate (Text S1; Scott, 2015) at groundwater wells at Site 3 (Figure 9a). Well ID is labeled. The letter "N" or "S" indicates groundwater wells in the northern or southern parts. The monthly gas relative production rates have very similar trend to the oil production rates and are not plotted here.

ALOS data (January 2007-March 2011), and the subsidence rate remains almost the same in the later Sentinel-1 data (November 2014 to February 2019) (Sample Points 11-16 in Figure 11). The surface deformations have trends similar to the observed ground water levels (Figure 10). Most areas in the north do not show obvious surface subsidence in the ALOS data but do exhibit subsidence in the later Sentinel-1 data (e.g., Sample Points 1-10 in Figures 9b and 11). The subsidence rate in the north shows both temporal and spatial correlation to the oil and gas production rate, especially gas production (Figures 9b-9d and 11). Due to the temporal data gap between the ALOS and Sentinel-1 data, the ALOS time series was extrapolated to match the Sentinel-1 time series assuming simple linear behavior.

As with Site 2, we simulated the 3-D pore pressure change due to fluid injection using MODFLOW for Site 3, using the same parameters (Table 1). The simulated pore pressure changes at most earthquake hypocenters are $\sim 2-20$ bars (Figures $8 \mathrm{~b}$ and $8 \mathrm{~d}$ ), clearly large enough to explain the earthquakes.

As discussed above, subsidence in the northern part of Site 3 is likely caused by the oil and gas extraction. A production well is identified as an oil well, gas well, or oil/gas well based on its dominant type of produced hydrocarbon. Usually, no matter how the well is classified, it produces both oil and gas. Most production wells at Site 3 are identified as oil wells, having a depth of $\sim 3.5 \mathrm{~km}$ (Figures 2a, S11, and S12). However, based on the spatial pattern of observed surface subsidence and oil and gas production density maps (Figures 9b-9d), the subsidence is more likely related to the gas rather than oil extraction. Considering the complex phase change of gas during the production, to simplify the process, we use the Okada model (Okada, 1992) to represent the equivalent source strength, which can generate the same magnitude of surface deformation as the real complex source.

Horizontal Okada patches at a depth of 3,360 m (average production well depth BLS, Figures 2a and S11) in a homogeneous and isotropic elastic half space were assumed. Figure 12b shows the down-sampled InSAR observation ( $0.5 \mathrm{~km}$ by $0.5 \mathrm{~km}$ interval) in the northern part of Site 3. Points with $1 \mathrm{~km}$ by $1 \mathrm{~km}$ interval 

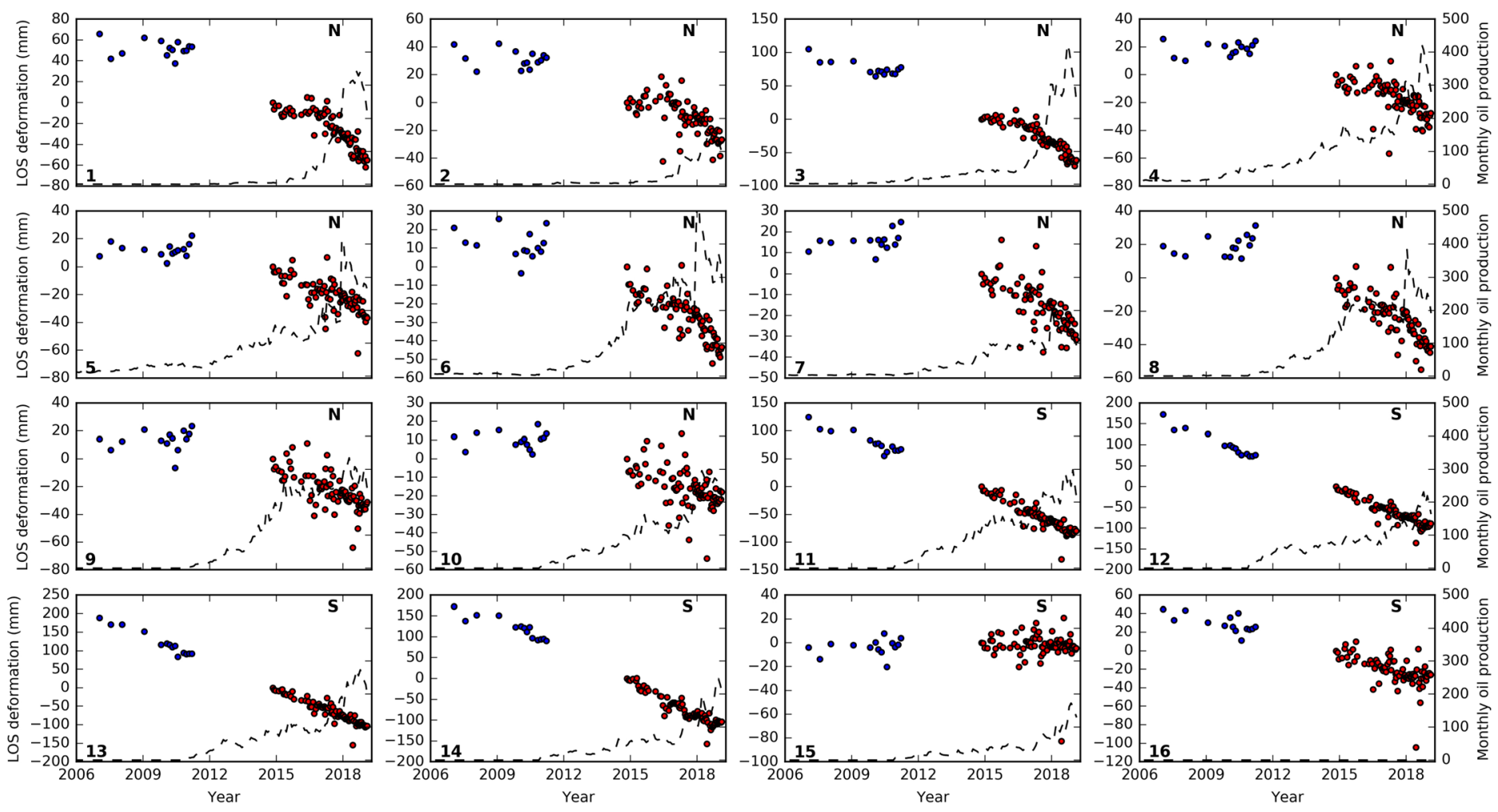

- - InSAR, ALOS $\quad \bullet$ InSAR, Sentinel-1

- - Oil production

Figure 11. Time series of InSAR LOS deformation and monthly oil relative production rate at sample points at Site 3 (Figure 9b). Points 1-10 are located in the northern part (labeled "N"). Points 11-16 are located in the southern part (labeled "S"). The monthly gas relative production rates have very similar trend

(Figure S10), and are not plotted here.

with a deformation value of 0 were added as background observation beyond the study area. The Okada tensile dislocation is constrained to be closing for all patches, that is, the tensile dislocations of all patches have the same (negative) sign. Nonpositive least squares were used for the inversion. For each time slice of the Sentinel-1 data, we inverted tensile dislocation relative to the first time slice (taken as the reference, deformation is 0) (Figure 12a).

We calculated the Coulomb stress change $\Delta \tau_{\mathrm{s}}+\mu \Delta \sigma_{\mathrm{n}}$ due to the tensile dislocation of Okada patches at the earthquake hypocenters for all Sentinel-1 InSAR slices. Poisson's ratio $=0.25$, Young's Modulus $=2 \times 10^{10} \mathrm{~Pa}$, and friction coefficient $=0.4$ were used. The calculated stress change of the time slice whose timing is closest to the timing of a certain earthquake is taken as the stress change for that earthquake. For every earthquake, stress changes based on all orientations (different combinations of strike, dip, and rake angles of a fault) in $5^{\circ}$ intervals were calculated. Without considering the real orientation of faults, the maximum $\Delta \tau_{\mathrm{s}}+\mu \Delta \sigma_{\mathrm{n}}$ at the time and hypocenter of earthquakes can reach $\sim 0.01-$ $0.1 \mathrm{MPa}(0.1-1.0 \mathrm{bar}$ ) (Figure 13a and 13b). This has the potential to induce earthquakes. However, it is much smaller than the Coulomb stress change $\mu p$ due to the pore pressure change (Figures $8 \mathrm{~b}$ and $8 \mathrm{~d}$ ).

\section{Discussion}

\subsection{Pore Pressure Change Due to Both Fluid Injection and Extraction at Sites 2 and 3}

Currently we have very limited knowledge about the permeability of the reservoir and surrounding rocks. Pore pressure changes due to oil and gas extraction are not considered in the above simulations using MODFLOW. This is based on the assumption that the reservoir's boundary has extremely low permeability, so that there should be almost no fluid exchange between the reservoir and surrounding rocks (otherwise it 

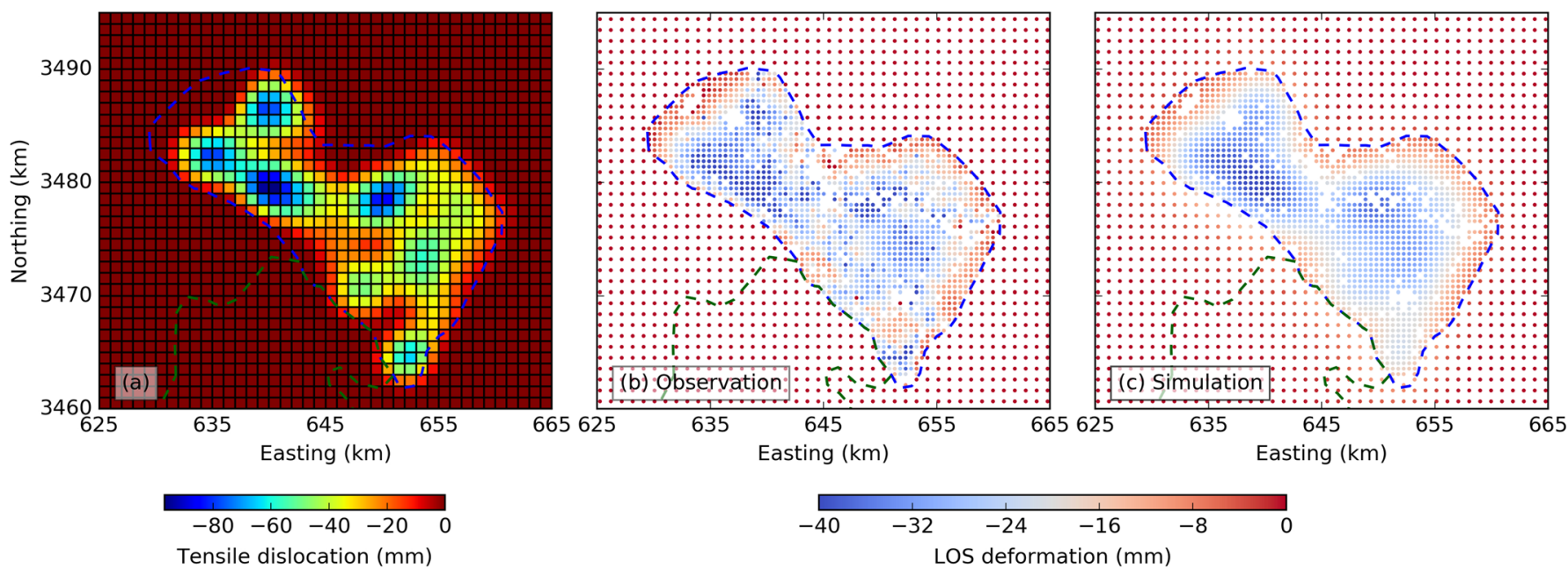

Tensile dislocation $(\mathrm{mm})$

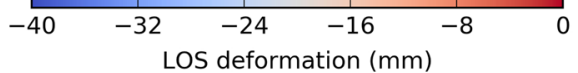

Figure 12. Inversion of Sentinel-1 InSAR deformation using Okada solution for subsidence in the northern part of Site 3 (Figure 9b). The last slice of the Sentinel-1 observation is used here as an example. (a) Inverted tensile dislocation of each Okada patch. Negative value means closing. The black grid shows the geometry of the Okada patches. (b) Down-sampled InSAR LOS observation after Gaussian filtering. (c) Simulated surface LOS deformation. The northern and southern parts are marked with blue and green dashed polygons for reference.

would not be a very good oil/gas reservoir). The pore pressure change outside the reservoir due to fluid extraction will therefore be quite small.

However, if the fluid exchange between the reservoir and surrounding rocks is nonnegligible, the pore pressure changes due to fluid extraction may change the result significantly. Possible reasons for this could include faults or natural fissures reactivated by human activities, for example, hydraulic fracturing or casing damage of wells. Assuming the reservoir has the same media property as the background rock, we rerun the pore pressure simulation for Sites 2 and 3 considering both fluid injection and extraction using parameters in Table 1. Since most wells in these two sites are oil wells, the effect of gas extraction is not considered. The oil production rate reported by the RRC does not include produced water (a byproduct of oil and gas extraction, usually reinjected). We use a water-to-oil ratio of 4 (Figures 3a-3c) for all wells to estimate the amount of the produced water along with the oil and gas production. In contrast to fluid injection, fluid extraction decreases pore pressure and generally inhibits fault slip. The simulated pore pressure changes at most earthquake hypocenters are still positive at Site 3 (Figure 14b), favoring fault slip. However, at Site 2 the pore pressure changes associated with most earthquakes become negative (Figure 14a).

\subsection{What Contributes to Coulomb Failure Stress Change at Site 3?}

The above simulation suggests that at Site 3 the Coulomb stress change $\mu p$ due to pore pressure change (Figure 8b, 8d, and 14b) is several tens of times larger than the stress change $\Delta \tau_{\mathrm{s}}+\mu \Delta \sigma_{\mathrm{n}}$ due to reservoir compaction (the simulated tensile dislocation of Okada patches) (Figure 13a). However, simulated pore pressure change can vary greatly depending on the hydraulic parameters, which are poorly known. For example, if we change Layer 3's hydraulic conductivity from $1 \times 10^{-9}$ to $1 \times 10^{-10} \mathrm{~m} / \mathrm{s}$ and diffusivity from 0.1 to $0.01 \mathrm{~m}^{2} / \mathrm{s}$, with other parameters remaining the same, the modeled pore pressure change at earthquake hypocenters decreases to $\sim 10 \%$ and $\sim 40 \%$ of the original pore pressure change at Site 2 (Figures $8 \mathrm{c}$ and 14c) and Site 3 (Figures $8 \mathrm{~d}$ and 14d), respectively. For Site 3, $\mu$ is still much larger than the $\Delta \tau_{\mathrm{s}}+\mu \Delta \sigma_{\mathrm{n}}$.

The orientation of the receiving fault also significantly affects the calculated Coulomb stress change $\Delta \tau_{\mathrm{s}}$ $+\mu \Delta \sigma_{\mathrm{n}}$. The state of stress analysis in Texas suggests that at Site 3 the maximum horizontal stress $\left(S_{\mathrm{hmax}}\right)$ has an orientation of $\sim 120^{\circ}$ (NW-SE) with a faulting regime of normal slip to normal/strike slip (Lund Snee \& Zoback, 2016, 2018). With this constraint, we calculated Coulomb stress changes $\Delta \tau_{\mathrm{s}}+\mu \Delta \sigma_{\mathrm{n}}$ for different possible combinations of strike, dip, and rake angles. Figures $13 \mathrm{c}$ and $13 \mathrm{~d}$ are two examples, while other combinations give similar results (Table S2 and Figure S13). For about half of the earthquakes, the sign of $\Delta \tau_{\mathrm{s}}+\mu \Delta \sigma_{\mathrm{n}}$ goes from positive to negative. The magnitude of the stress change for the remaining earthquakes becomes smaller. In this case the pore pressure change contributes even more to fault failure. 

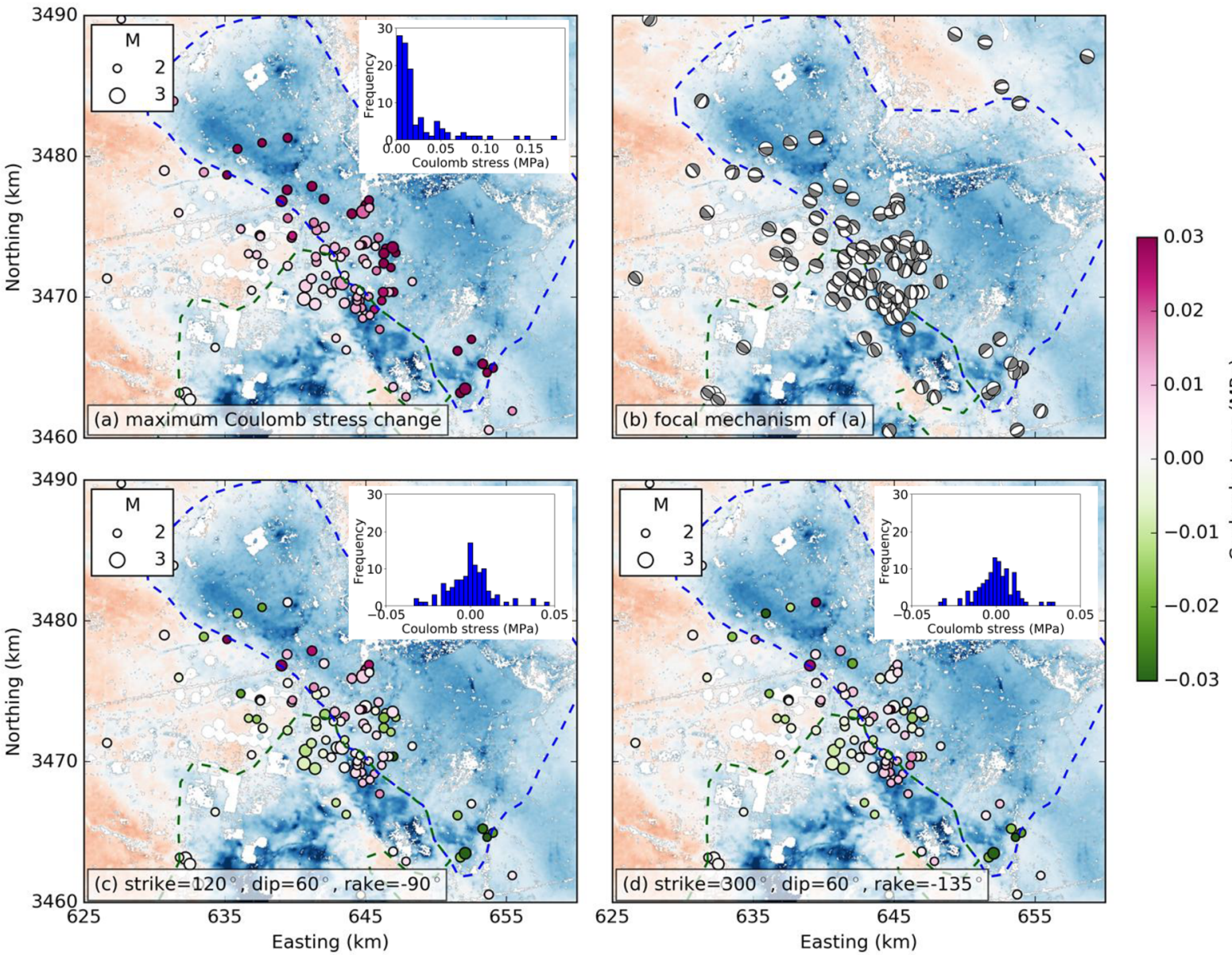

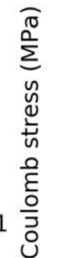

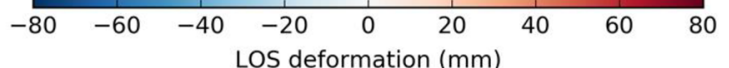

Figure 13. (a) Maximum possible Coulomb stress change $\Delta \tau_{\mathrm{s}}+\mu \Delta \sigma_{\mathrm{n}}$ at earthquake hypocenters, Site 3. (b) Corresponding focal mechanisms of the maximum Coulomb stress changes shown in (a). (c and d) The Coulomb stress change assuming certain fault orientations. Failure is promoted when Coulomb stress change is positive. The background image is the cumulative LOS deformation from Sentinel-1 data. The northern and southern parts are marked with blue and green dashed polygons for reference. The inserts in (a), (b), and (d) are histograms of the Coulomb stress changes at earthquake hypocenters.

Surface deformation and seismicity at Site 3 have patterns that are similar in some respects to what has been observed in the Raton Basin, along the Colorado-New Mexico border, where coal bed methane extraction is accompanied by significant wastewater injection. Spatial and temporal correlations (Rubinstein et al., 2014) and numerical modeling of pore pressure changes (Nakai et al., 2017) suggest that the majority of seismicity in the Raton Basin since 2001 is induced by wastewater injection. Some surface subsidence is also observed (Barnhart et al., 2014) and may reflect hydrocarbon withdrawal.

\subsection{How Do Depth Uncertainties of Seismicity Affect the Result?}

The calculatedmagnitude of pore pressure declines dramatically with distance from the injection site. Therefore, the injection location and the pore pressure calculation location (earthquake hypocenters in our case) are critical parameters in the numerical simulation. The TexNet catalog we used provides the horizontal and vertical (depth) uncertainties of seismic events. The depth uncertainty is about twice as large as the horizontal uncertainty in our study area (Figure S1). The average depth uncertainties at Sites 2 and 3 are 1.9 and $1.6 \mathrm{~km}$, respectively (Figure S14). Below we assess how these depth uncertainties affect the simulated pore pressure changes and estimated media properties.

Most earthquakes occurred below the depth of injection at Sites 2 and 3 (Figure 2a). For each earthquake, we added the depth uncertainty to the event depth. Then, we recalculated pore pressure changes using the 
Site 2
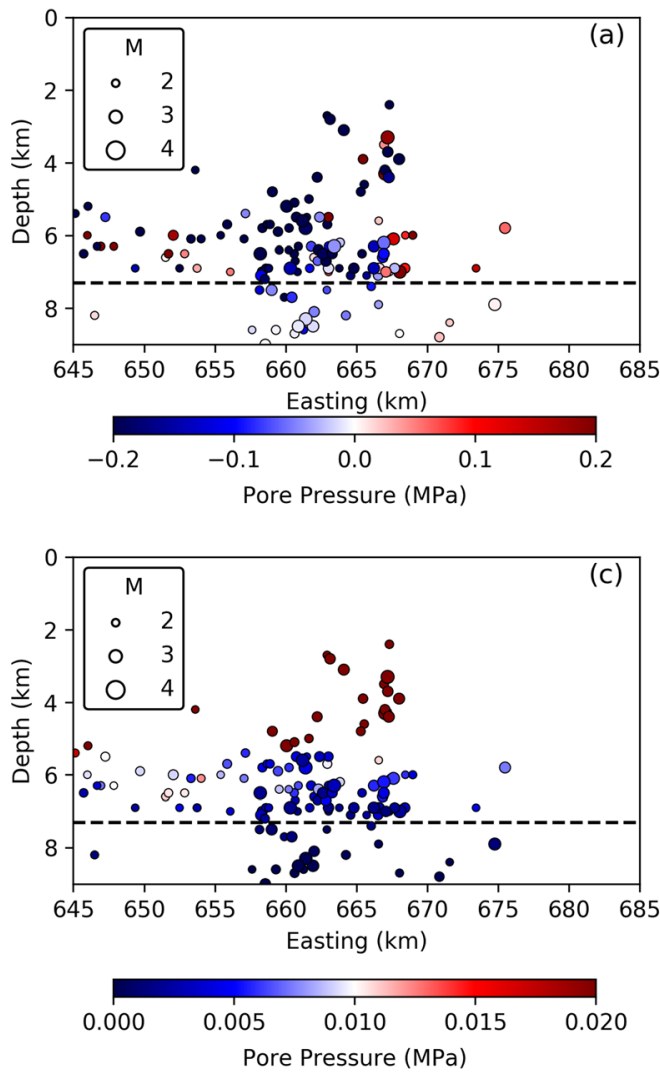

Site 3

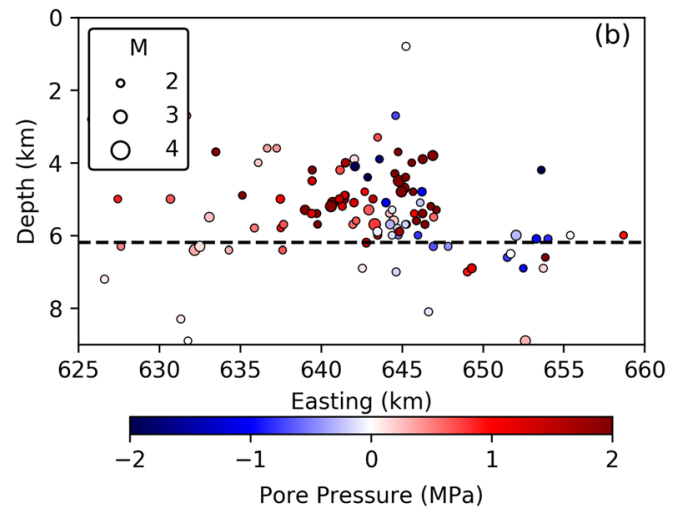

Figure 14. Simulated pore pressure changes at earthquake hypocenters (colored circles) due to fluid injection and extraction ( $\mathrm{a}, \mathrm{b}$ ), and due to fluid injection only using a lower hydraulic conductivity $K$ for model Layer 3 (c, d) for Sites 2 (a, c) and 3 (b, d). Note the different scales of color bars.

parameters in Table 1. This provides a lower bound to the simulated pore pressure changes since the further away from the injection site, the smaller the pore pressure change. At Site 2, the newly simulated pore pressure changes for most earthquake hypocenters decrease to only a few KPa (Figure 15a). At Site 3, the pore pressure changes for many earthquake hypocenters still reach $0.1 \mathrm{MPa}$ (1 bar) (Figure 15b).

We tested the sensitivity to the hydraulic conductivity $K$ in the model by increasing $K$ in Layers 4 and 5 by a factor of 10 while keeping $S_{S}$ constant ( $D$ increases by a factor of 10 based on equation 5 ). The new values still fall within the wide range of published values for hydraulic parameters for similar lithologies (Duffield, 2019). Using these new parameters, the simulated pore pressure changes at the hypocenters of most earthquakes (depth uncertainty added) at Site 2 and Site 3 reach 0.05 and $0.5 \mathrm{MPa}$, respectively (Figures $15 \mathrm{c}$ and $15 \mathrm{~d})$, still reaching the assumed threshold ( 0.1 MPa) to induce earthquakes. These calculations suggest that even when depth uncertainties of earthquakes are considered, pore pressure changes due to fluid injection are still likely to be the main cause of the induced earthquakes.

\subsection{Comparing the Three Study Sites}

Earthquakes at Sites 2 and 3 have a NW-SE trend, in approximate agreement with the orientation of surrounding faults, but occurred on previously unmapped faults (Figure 1a). In terms of depth, most earthquakes at Site 3 are above the basement, while most earthquakes at Site 2 distribute from the production layer (shale) to the basement (Figure 2). Sites 2 and 3 have injection wells that have similar or even larger injection rates compared to the wells at Site 1; however, no surface uplift is observed at Sites 2 and 3. While our simulations indicate large pore pressure changes at Site 1 (Figure $4 \mathrm{~b}$ ), no earthquakes are reported. Sites 2 and 3 are close to each other and probably have similar rock properties, but the magnitudes of earthquakes at Site 2 are, in general, larger than those at Site 3 (Figures 1a and 2a), even though simulated 
Site 2
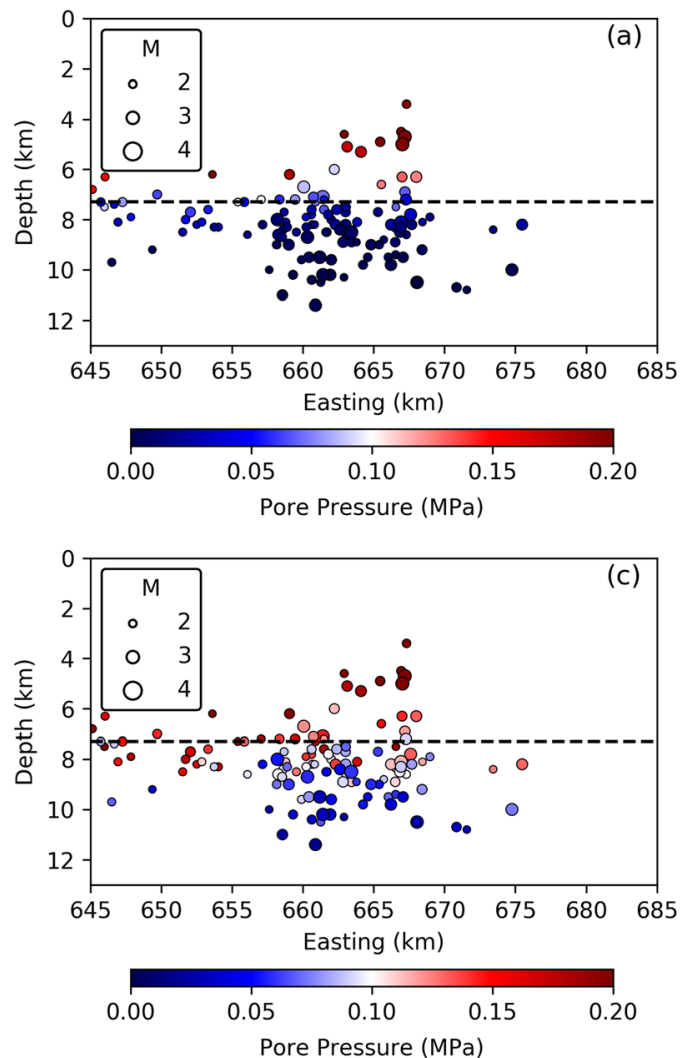

Site 3
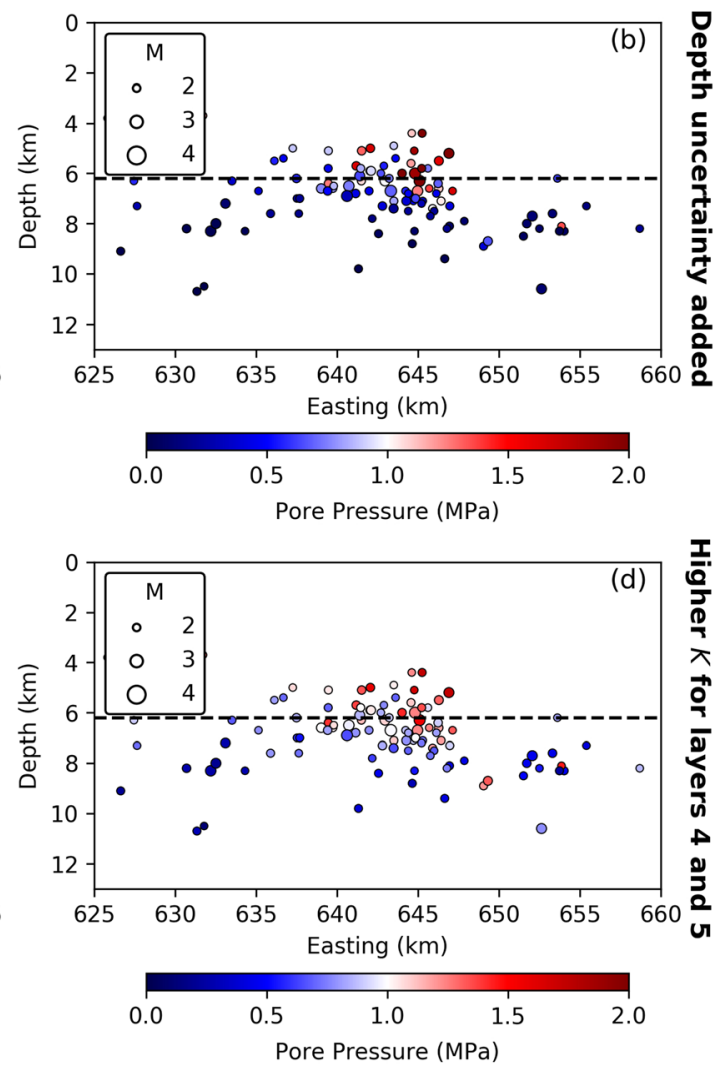

Figure 15. Simulated pore pressure changes at the new earthquake hypocenters (colored circles) which were shifted by adding the depth uncertainties (Figure S14) at Sites 2 (a, c) and 3 (b, d). The top is based on the parameters in Table 1. The bottom used higher (10 times the original value) hydraulic conductivities $K$ for Model Layers 4 and 5, while $S_{S}$ remains the same. Note the different scales of color bars.

pore pressure is smaller at Site 2 (Figures 8, 14, and 15). Sites 2 and 3 may have different reservoir properties, assuming that for both sites earthquakes are induced by increased pore pressure. The reservoir in Site 2 may have relatively low permeability, limiting fluid exchange with surrounding rocks. These similarities and differences suggest the importance of local rock structures and properties in predicting the occurrence of induced earthquakes.

Our study, as well as many others, point to fluid injection as the primary cause of rapidly increasing seismic rate in West Texas (e.g., Frohlich et al., 2016; Skoumal et al., 2020) and elsewhere (e.g., Hincks et al., 2018; Keranen et al., 2014; Weingarten et al., 2015), likely due to changes in pore pressure. Ideally these types of studies will eventually help to establish thresholds for safe fluid injection, below which significant seismicity would not occur. While there is an obvious positive correlation between injected fluid rate/volume and the number of earthquakes at our three study sites (e.g., Figures 2 and 3), uncertainties in the estimated pore pressure and incompleteness of the seismic catalog in the early years preclude firm conclusions. However, the limited data allow some crude constraints. For Sites 1 and 2, significant seismicity does not occur for injection rates below about 2 million barrels per month. For Site 3, this threshold is about 8 million barrels per month (Figure 3a-3c). These thresholds may be biased by the site area size. Density maps of fluid injection rate/volume and earthquake distribution at regional scale could be considered for future analysis.

\section{Conclusions}

Temporal and spatial correlations suggest that recent increases in seismicity in West Texas are likely related to oil and gas production. We use satellite InSAR time series (ALOS 2007-2011 and Sentinel-12014-2019) to measure surface deformation at three sites in West Texas and relate it to seismicity, fluid injection/extraction, and modeled pore pressure changes at depth. At Site 1, uplift is observed but 
seismicity is absent, despite large increases in calculated pore pressure from fluid injection. This may reflect no faults at depth at Site 1. Sites 2 and 3 both experience elevated seismic rates likely associated with increased pore pressure due to fluid injection, but surface deformation mainly reflects shallow fluid withdrawal, either ground water or natural gas.

Similarities and differences between our three study sites suggest the importance of local rock structures and properties in determining seismic behavior and sensitivity to injection. Combining data on ground deformation, seismicity, and injection/extraction volumes with numerical models of pressure/stress change provides a powerful tool to improve our understanding of the relationship between fluid injection/extraction, reservoir dynamics, and induced seismicity and could lead to better mitigation strategies. Tighter constraints on media properties from independent data sources, better location of earthquake hypocenters, and improved 3-D fault mapping can reduce the uncertainties in these numerical models and provide better predictions of whether a given oil and gas field is prone to induced seismicity and how it can be reduced.

\section{Acknowledgments}

We thank Jochen Braunmiller and Qian Yang for valuable discussions. We thank Manoochehr Shirzaei and an anonymous reviewer for their careful and constructive comments on an earlier version of this paper. Thanks also go to Editors Paul Tregoning and Andy Hooper for their patience and feedback. Rongjiang Wang provided the code for pore pressure and deformation modeling in poroelastic media. ALOS SAR data were provided by the Japan Aerospace Exploration Agency (JAXA). Sentinel-1 SAR data were provided by the European Space Agency (ESA). SAR data were downloaded from the Alaska Satellite Facility (https://www. asf.alaska.edu/). Sentinel-2 data were provided by ESA and were downloaded from the Copernicus Open Access Hub (https://scihub.copernicus.eu/). SRTM DEM was downloaded online (from https://topex.ucsd.edu/gmtsar/demgen/). We thank the Railroad Commission of Texas (Texas RRC) for providing oil and gas well information. The water level measurements were extracted from the Groundwater Database Reports provided by the Texas Water Development Board, downloaded online (from http://www.twdb. texas.gov/groundwater/data/gwdbrpt. asp). GPS data were downloaded from the Nevada Geodetic Laboratory (http://geodesy.unr.edu/). This study was supported by a NASA Earth and Space Science Fellowship (Grant 80NSSC17K0320).

\section{References}

Agram, P. S., Jolivet, R., Riel, B., Lin, Y. N., Simons, M., Hetland, E., et al. (2013). New radar interferometric time series analysis toolbox released. Eos, Transactions American Geophysical Union, 94(7), 69-70.

Agram, P.S., Jolivet, R. and Simons, M., Generic InSAR Analysis Toolbox (GIAnT), User Guide. 2016.

Bakker, M., Post, V., Langevin, C. D., Hughes, J. D., White, J. T., Starn, J. J., \& Fienen, M. N. (2016). Scripting MODFLOW model development using Python and FloPy. Groundwater, 54(5), 733-739.

Barnhart, W. D., Benz, H. M., Hayes, G. P., Rubinstein, J. L., \& Bergman, E. (2014). Seismological and geodetic constraints on the $2011 M_{w} 5$. 3 Trinidad, Colorado earthquake and induced deformation in the Raton Basin. Journal of Geophysical Research: Solid Earth, 119, 7923-7933. https://doi.org/10.1002/2014JB011227

Barnhart, W. D., Yeck, W. L., \& McNamara, D. E. (2018). Induced earthquake and liquefaction hazards in Oklahoma, USA: Constraints from InSAR. Remote Sensing of Environment, 218, 1-12.

Berardino, P., Fornaro, G., Lanari, R., \& Sansosti, E. (2002). A new algorithm for surface deformation monitoring based on small baseline differential SAR interferograms. IEEE Transactions on Geoscience and Remote Sensing, 40(11), 2375-2383.

Blewitt, G., Hammond, W. C., \& Kreemer, C. (2018). Harnessing the GPS data explosion for interdisciplinary science. Eos, 99, 1-2. Boghici, R. (2008). Changes in water levels in Texas, 1990 to 2000. Texas Water Development Board, report 371.

Boltz, M. S., Pankow, K. L., \& McCarter, M. K. (2014). Fine details of mining-induced seismicity at the Trail Mountain Coal Mine using modified hypocentral relocation techniques. Bulletin of the Seismological Society of America, 104(1), 193-203.

Brown, M. R., \& Ge, S. (2018). Small earthquakes matter in injection-induced seismicity. Geophysical Research Letters, 45, 5445-5453. https://doi.org/10.1029/2018GL077472

Brown, M. R., Ge, S., Sheehan, A. F., \& Nakai, J. S. (2017). Evaluating the effectiveness of induced seismicity mitigation: Numerical modeling of wastewater injection near Greeley, Colorado. Journal of Geophysical Research: Solid Earth, 122, 6569-6582. https://doi.org/ 10.1002/2017JB014456

Bruun, B., Jackson, K., Lake, P. and Walker J., 2016. Texas aquifers study_Groundwater quantity, quality, flow, and contributions to surface water. http://www.twdb.texas.gov/groundwater/docs/studies/TexasAquifersStudy_2016.pdf

Cochran, E. S., Vidale, J. E., \& Tanaka, S. (2004). Earth tides can trigger shallow thrust fault earthquakes. Science, 306(5699), 1164-1166. https://doi.org/10.1126/science.1103961

Duffield, G.M. (2019). Representative values of hydraulic properties. AQTESOLV.

Ellsworth, W. L. (2013). Science, 341(6142), -Injection-induced earthquakes.

Engle, M. A., Reyes, F. R., Varonka, M. S., Orem, W. H., Ma, L., Ianno, A. J., et al. (2016). Geochemistry of formation waters from the Wolfcamp and "Cline" shales: Insights into brine origin, reservoir connectivity, and fluid flow in the Permian basin, USA. Chemical Geology, 425, 76-92.

Farr, T. G., Rosen, P. A., Caro, E., Crippen, R., Duren, R., Hensley, S., et al. (2007). The shuttle radar topography mission. Reviews of Geophysics, 45, RG2004. https://doi.org/10.1029/2005RG000183

Frohlich, C., \& Brunt, M. (2013). Two-year survey of earthquakes and injection/production wells in the Eagle Ford shale, Texas, prior to the $M_{w} 4.820$ October 2011 earthquake. Earth and Planetary Science Letters, 379, 56-63.

Frohlich, C., DeShon, H., Stump, B., Hayward, C., Hornbach, M., \& Walter, J. I. (2016). A historical review of induced earthquakes in Texas. Seismological Research Letters, 87(4), 1022-1038.

Goebel, T. H. W., Weingarten, M., Chen, X., Haffener, J., \& Brodsky, E. E. (2017). The $2016 M_{w} 5.1$ Fairview, Oklahoma earthquakes: Evidence for long-range poroelastic triggering at $>40 \mathrm{~km}$ from fluid disposal wells. Earth and Planetary Science Letters, 472 , 50-61.

Hainzl, S., Kraft, T., Wassermann, J., Igel, H., \& Schmedes, E. (2006). Evidence for rainfall-triggered earthquake activity. Geophysical Research Letters, 33, L19303. https://doi.org/10.1029/2006GL027642

Hansen, P. C. (1999). The L-curve and its use in the numerical treatment of inverse problems.

Harbaugh, A.W., 2005. MODFLOW-2005, the US Geological Survey modular ground-water model: The ground-water flow process (pp. 6-A16). Reston, VA: US Department of the Interior, US Geological Survey.

Hearn, E. H., \& Bürgmann, R. (2005). The effect of elastic layering on inversions of GPS data for coseismic slip and resulting stress changes: Strike-slip earthquakes. Bulletin of the Seismological Society of America, 95(5), 1637-1653.

Hearn, E. H., Koltermann, C., \& Rubinstein, J. L. (2018). Numerical models of pore pressure and stress changes along basement faults due to wastewater injection: Applications to the 2014 Milan, Kansas earthquake. Geochemistry, Geophysics, Geosystems, 19, 1178-1198. https://doi.org/10.1002/2017GC007194

Hills, J. M. (1984). Sedimentation, tectonism, and hydrocarbon generation in Delaware basin, West Texas and southeastern New Mexico. AAPG Bulletin, 68(3), 250-267. 
Hincks, T., Aspinall, W., Cooke, R., \& Gernon, T. (2018). Oklahoma's induced seismicity strongly linked to wastewater injection depth. Science, 359(6381), 1251-1255. https://doi.org/10.1126/science.aap7911

Hornbach, M. J., DeShon, H. R., Ellsworth, W. L., Stump, B. W., Hayward, C., Frohlich, C., et al. (2015). Causal factors for seismicity near Azle, Texas. Nature Communications, 6, 6728.

Hornbach, M. J., Jones, M., Scales, M., DeShon, H. R., Magnani, M. B., Frohlich, C., et al. (2016). Ellenburger wastewater injection and seismicity in North Texas. Physics of the Earth and Planetary Interiors, 261, 54-68.

Hough, S. E., Tsai, V. C., Walker, R., \& Aminzadeh, F. (2017). Was the $M_{w} 7.51952$ Kern County, California, earthquake induced (or triggered)? Journal of Seismology, 21(6), 1613-1621.

Johann, L., Shapiro, S. A., \& Dinske, C. (2018). The surge of earthquakes in Central Oklahoma has features of reservoir-induced seismicity. Scientific Reports, 8(1), 11505.

Karegar, M. A., Dixon, T. H., Malservisi, R., Yang, Q., Hossaini, S. A., \& Hovorka, S. D. (2015). GPS-based monitoring of surface deformation associated with $\mathrm{CO}_{2}$ injection at an enhanced oil recovery site. International Journal of Greenhouse Gas Control, 41, 116-126.

Keranen, K. M., Weingarten, M., Abers, G. A., Bekins, B. A., \& Ge, S. (2014). Sharp increase in Central Oklahoma seismicity since 2008 induced by massive wastewater injection. Science, 345(6195), 448-451. https://doi.org/10.1126/science.1255802

Kim, J. W., \& Lu, Z. (2018). Association between localized geohazards in West Texas and human activities, recognized by Sentinel-1A/B satellite radar imagery. Scientific Reports, 8(1), 4727.

Kümpel, H. J. (1991). Poroelasticity: Parameters reviewed. Geophysical Journal International, 105(3), 783-799.

Lin, J., \& Stein, R. S. (2004). Stress triggering in thrust and subduction earthquakes and stress interaction between the southern San Andreas and nearby thrust and strike-slip faults. Journal of Geophysical Research, 109, B02303. https://doi.org/10.1029/2003JB002607

Lomax, A., \& Savvaidis, A. (2019). Improving absolute earthquake location in West Texas using probabilistic, proxy ground-truth station corrections. Journal of Geophysical Research: Solid Earth, 124, 11,447-11,465. https://doi.org/10.1029/2019JB017727

Lund Snee, J. E. L., \& Zoback, M. D. (2016). State of stress in Texas: Implications for induced seismicity. Geophysical Research Letters, 43, 10-208. https://doi.org/10.1002/2016GL070974

Lund Snee, J. E. L., \& Zoback, M. D. (2018). State of stress in the Permian basin, Texas and New Mexico: Implications for induced seismicity. The Leading Edge, 37(2), 127-134.

Matchus, E.J., Jones, T.S., 1984. East-west cross section through Permian basin of West Texas. West Texas Geological Society.

Menke, W. (2018). Geophysical data analysis: Discrete inverse theory. New York: Academic press.

Mossop, A., \& Segall, P. (1999). Volume strain within the geysers geothermal field. Journal of Geophysical Research, 104(B12), 29,113-29,131.

Nakai, J. S., Weingarten, M., Sheehan, A. F., Bilek, S. L., \& Ge, S. (2017). A possible causative mechanism of Raton Basin, New Mexico and Colorado earthquakes using recent seismicity patterns and pore pressure modeling. Journal of Geophysical Research: Solid Earth, 122, 8051-8065. https://doi.org/10.1002/2017JB014415

Ogwari, P. O., DeShon, H. R., \& Hornbach, M. J. (2018). The Dallas-Fort Worth airport earthquake sequence: Seismicity beyond injection period. Journal of Geophysical Research: Solid Earth, 123, 553-563. https://doi.org/10.1002/2017JB015003

Ogwari, P. O., \& Horton, S. P. (2016). Numerical model of pore-pressure diffusion associated with the initiation of the 2010-2011 GuyGreenbrier, Arkansas earthquakes. Geofluids, 16(5), 954-970.

Okada, Y. (1992). Internal deformation due to shear and tensile faults in a half-space. Bulletin of the Seismological Society of America, 82(2), 1018-1040.

Peinke, J., Matcharashvili, T., Chelidze, T., Gogiashvili, J., Nawroth, A., Lursmanashvili, O., \& Javakhishvili, Z. (2006). Influence of periodic variations in water level on regional seismic activity around a large reservoir: Field data and laboratory model. Physics of the Earth and Planetary Interiors, 156(1-2), 130-142.

Raleigh, C. B., Healy, J. H., \& Bredehoeft, J. D. (1976). An experiment in earthquake control at Rangely, Colorado. Science, 191(4233), 1230-1237.

Reasenberg, P. A., \& Simpson, R. W. (1992). Response of regional seismicity to the static stress change produced by the Loma Prieta earthquake. Science, 255(5052), 1687-1690. https://doi.org/10.1126/science.255.5052.1687

Robinson, K., 1988. Petroleum geology and hydrocarbon plays of the Permian basin petroleum province West Texas and southeast New Mexico. U.S. Geological Survey, Open-File Report 88-450Z.

Rosepiler, M. J., \& Reilinger, R. (1977). Land subsidence due to water withdrawal in the vicinity of Pecos, Texas. Engineering Geology, 11(4), 295-304.

Rubinstein, J. L., Ellsworth, W. L., McGarr, A., \& Benz, H. M. (2014). The 2001-present induced earthquake sequence in the Raton Basin of northern New Mexico and southern Colorado. Bulletin of the Seismological Society of America, 104(5), 2162-2181.

Rubinstein, J. L., \& Mahani, A. B. (2015). Myths and facts on wastewater injection, hydraulic fracturing, enhanced oil recovery, and induced seismicity. Seismological Research Letters, 86(4), 1060-1067.

Ruppel, S.C., Jones, R.H., Breton, C.L. and Kane, J.A., 2005. Preparation of maps depicting geothermal gradient and Precambrian structure in the Permian basin. Contract report to the US Geological Survey Order, (04CRSA0834).

Saar, M. O., \& Manga, M. (2003). Seismicity induced by seasonal groundwater recharge at Mt. Hood, Oregon. Earth and Planetary Science Letters, 214(3-4), 605-618.

Sandwell, D., Mellors, R., Tong, X., Wei, M., \& Wessel, P. (2011a). Open radar interferometry software for mapping surface deformation. Eos, Transactions American Geophysical Union, 92(28), 234-234.

Sandwell, D., Mellors, R., Tong, X., Wei, M., \& Wessel, P. (2011b). Gmtsar: An insar processing system based on generic mapping tools. UC San Diego: Scripps Institution of Oceanography. Retrieved from:. http://escholarship.org/uc/item/8zq2c02m

Savvaidis, A., Young, B., Huang, G. C. D., \& Lomax, A. (2019). TexNet: A statewide seismological network in Texas. Seismological Research Letters. https://doi.org/10.1785/0220180350

Scott, D. W. (2015). Multivariate density estimation: Theory, practice, and visualization. New York: John Wiley \& Sons.

Segall, P. (1989). Earthquakes triggered by fluid extraction. Geology, 17(10), 942-946.

Segall, P. (1992). Induced stresses due to fluid extraction from axisymmetric reservoirs. Pure and Applied Geophysics, 139(3-4), 535-560.

Segall, P., Grasso, J. R., \& Mossop, A. (1994). Poroelastic stressing and induced seismicity near the Lacq gas field, southwestern France. Journal of Geophysical Research, 99(B8), 15,423-15,438.

Shirzaei, M., Ellsworth, W. L., Tiampo, K. F., González, P. J., \& Manga, M. (2016). Surface uplift and time-dependent seismic hazard due to fluid injection in eastern Texas. Science, 353(6306), 1416-1419. https://doi.org/10.1126/science.aag0262

Shirzaei, M., Manga, M., \& Zhai, G. (2019). Hydraulic properties of injection formations constrained by surface deformation. Earth and Planetary Science Letters, 515, 125-134. 
Sinclair, T.D., 2007. The generation and continued existence of overpressure in the Delaware Basin, Texas (Doctoral dissertation, Durham University).

Skoumal, R. J., Barbour, A. J., Brudzinski, M. R., Langenkamp, T., \& Kaven, J. O. (2020). Induced seismicity in the Delaware Basin, Texas. Journal of Geophysical Research: Solid Earth, 125. https://doi.org/10.1029/2019JB018558

Stein, R. S. (1999). The role of stress transfer in earthquake occurrence. Nature, 402(6762), 605-609.

Toda, S., Stein, R. S., Richards-Dinger, K., \& Bozkurt, S. B. (2005). Forecasting the evolution of seismicity in southern California: Animations built on earthquake stress transfer. Journal of Geophysical Research, 110, B05S16. https://doi.org/10.1029/2004JB003415

Toda, S., Stein, R.S., Sevilgen, V. and Lin, J., 2011. Coulomb 3.3 graphic-rich deformation and stress-change software for earthquake, tectonic, and volcano research and teaching-user guide. U.S. Geological Survey, open-file report 2011-1060.

Vasco, D. W., Ferretti, A., \& Novali, F. (2008). Reservoir monitoring and characterization using satellite geodetic data: Interferometric synthetic aperture radar observations from the Krechba field, Algeria. Geophysics, 73(6), WA113-WA122.

Vasco, D. W., Harness, P., Pride, S., \& Hoversten, M. (2016). Estimating fluid-induced stress change from observed deformation. Geophysical Journal International, 208(3), 1623-1642.

Vasco, D. W., Rucci, A., Ferretti, A., Novali, F., Bissell, R. C., Ringrose, P. S., et al. (2010). Satellite-based measurements of surface deformation reveal fluid flow associated with the geological storage of carbon dioxide. Geophysical Research Letters, 37, L03303. https://doi. org/10.1029/2009GL041544

Walsh, F. R., \& Zoback, M. D. (2015). Oklahoma's recent earthquakes and saltwater disposal. Science Advances, 1(5), e1500195.

Wang, R., \& Kümpel, H. J. (2003). Poroelasticity: Efficient modeling of strongly coupled, slow deformation processes in a multilayered half-space. Geophysics, 68(2), 705-717.

Weingarten, M., Ge, S., Godt, J. W., Bekins, B. A., \& Rubinstein, J. L. (2015). High-rate injection is associated with the increase in US mid-continent seismicity. Science, 348(6241), 1336-1340. https://doi.org/10.1126/science.aab1345

Yang, Q., Zhao, W., Dixon, T. H., Amelung, F., Han, W. S., \& Li, P. (2015). InSAR monitoring of ground deformation due to $\mathrm{CO}_{2}$ injection at an enhanced oil recovery site, West Texas. International Journal of Greenhouse Gas Control, 41, $20-28$.

Yeck, W. L., Hayes, G. P., McNamara, D. E., Rubinstein, J. L., Barnhart, W. D., Earle, P. S., \& Benz, H. M. (2017). Oklahoma experiences largest earthquake during ongoing regional wastewater injection hazard mitigation efforts. Geophysical Research Letters, $44,711-717$. https://doi.org/10.1002/2016GL071685

Yeck, W. L., Weingarten, M., Benz, H. M., McNamara, D. E., Bergman, E. A., Herrmann, R. B., et al. (2016). Far-field pressurization likely caused one of the largest injection induced earthquakes by reactivating a large preexisting basement fault structure. Geophysical Research Letters, 43, 10-198. https://doi.org/10.1002/2016GL070861

Yerkes, R. F., \& Castle, R. O. (1976). Seismicity and faulting attributable to fluid extraction. Engineering Geology, 10(2-4), 151-167.

Zhai, G., \& Shirzaei, M. (2018). Fluid injection and time-dependent seismic hazard in the Barnett shale, Texas. Geophysical Research Letters, 45, 4743-4753. https://doi.org/10.1029/2018GL077696

Zhang, Y., Edel, S. S., Pepin, J., Person, M., Broadhead, R., Ortiz, J. P., et al. (2016). Exploring the potential linkages between oil-field brine reinjection, crystalline basement permeability, and triggered seismicity for the Dagger Draw oil field, southeastern New Mexico, USA, using hydrologic modeling. Geofluids, 16(5), 971-987.

Zhang, Y., Person, M., Rupp, J., Ellett, K., Celia, M. A., Gable, C. W., et al. (2013). Hydrogeologic controls on induced seismicity in crystalline basement rocks due to fluid injection into basal reservoirs. Groundwater, 51(4), 525-538. 